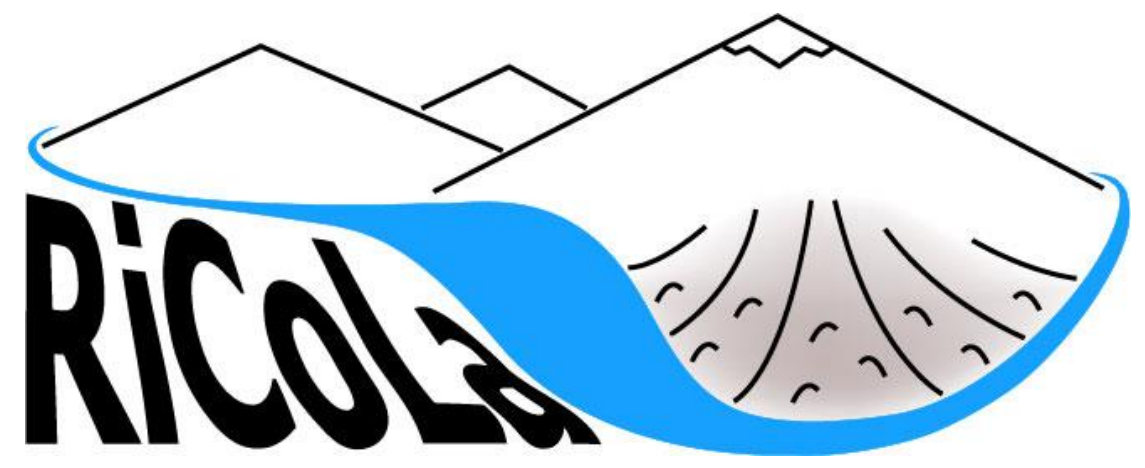

\title{
Detection and analysis of landslide- induced river course changes and lake formation (RiCoLa)
}

\section{Final Project Report}

Günther Prasicek ${ }^{1,3}$, Daniel Hölbling ${ }^{2}$, Anne-Laure Argentin ${ }^{1}$, Lorena Abad ${ }^{2}$, Zahra Dabiri $^{2}$

${ }^{1}$ Department of Geography and Geology, University of Salzburg

${ }^{2}$ Interfaculty Department of Geoinformatics - Z_GIS, University of Salzburg

${ }^{3}$ Institute of Earth Surface Dynamics, University of Lausanne

ISBN-Online: 978-3-7001-8986-2

DOI: 10.1553/ESS-RiCoLa 


\section{Table of contents}

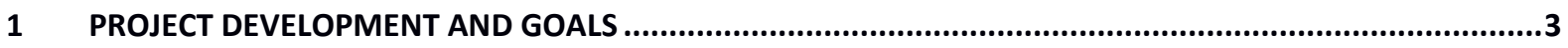

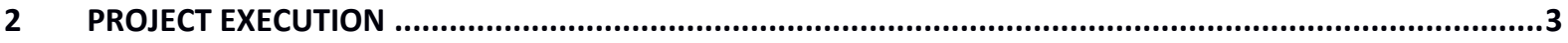

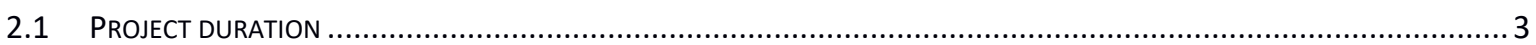

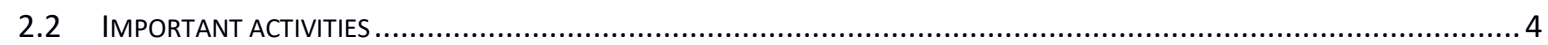

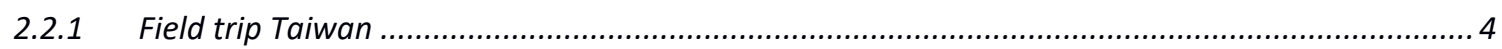

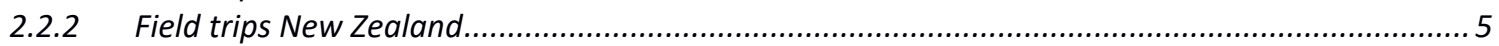

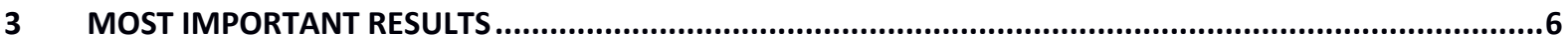

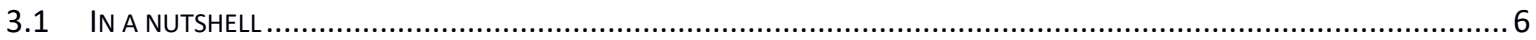

3.2 MAPPING AND MONITORING OF RIVER-DAMMING LANDSLIDES ON SATELLITE IMAGES ......................................... 7

3.2.1 Analyzing the evolution of the Butangbunasi landslide ................................................................ 7

3.2.2 Mapping landslides that created landslide dams and monitoring of the dammed lakes in Taiwan

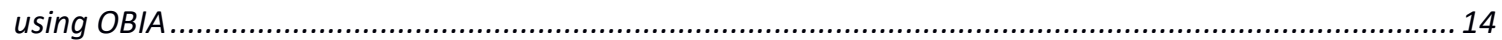

3.3 DETECTION OF LANDSLIDE-DAMMED LAKES ON TIME SERIES OF SATELLITE IMAGES .................................................. 18

3.3.1 Landslide-dammed lake mapping and monitoring approach ................................................ 19

3.3.2 Landslide-dammed lake categorization based on spatio-temporal patterns .............................22

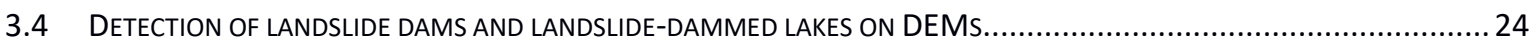

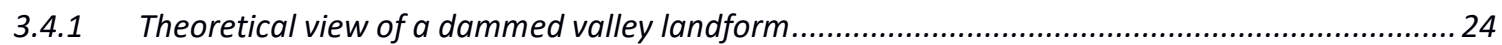

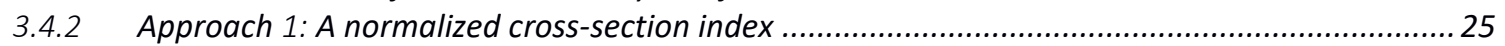

3.4.3 Approach 2: upstream region growing ................................................................................. 26

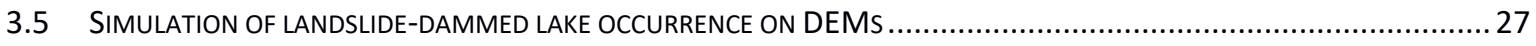

3.5.1 Study 1: Potential landslide-dammed lakes in Austria ............................................................28

3.5.2 Study 2: Global scaling of landslide and dammed lake characteristics..................................... 31

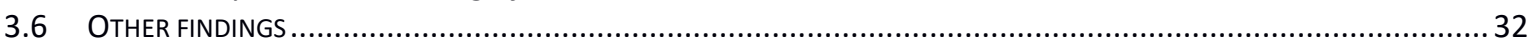

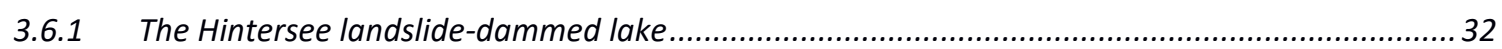

3.6.2 Assessment of landslide-induced geomorphological changes using Sentinel-1 and Sentinel-2 data 34

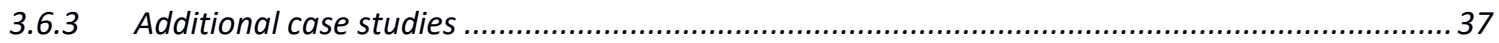

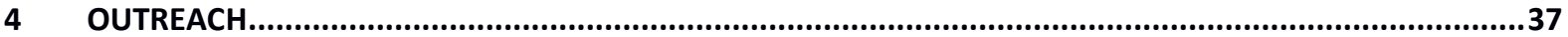

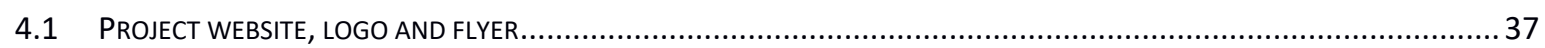

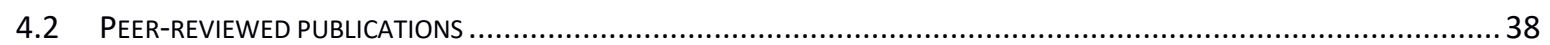

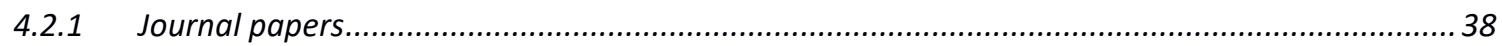

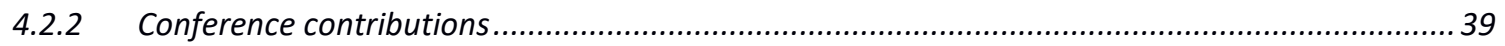

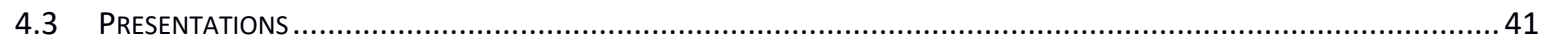

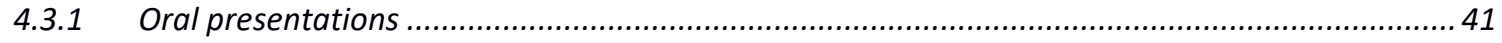

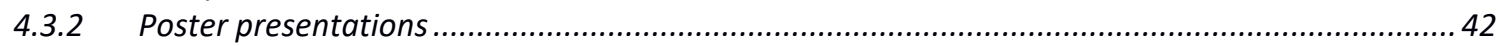

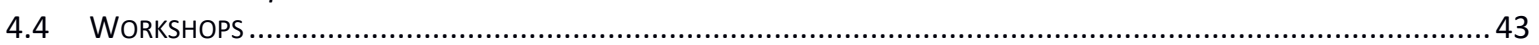

4.4.1 Visit at the Disaster Prevention Education Center in Taiwan.....................................................43

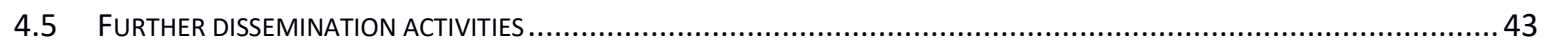

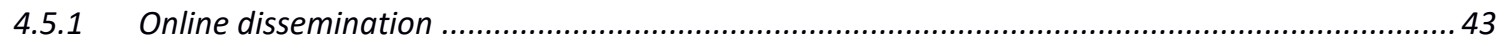

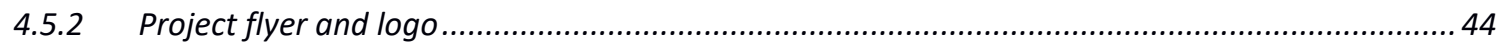

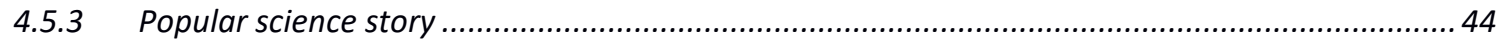




\section{Project development and goals}

Landslides are among the most serious threats to human lives and infrastructure in mountain ranges worldwide. Beyond the direct hazard through the moving mass, landslides can initiate natural hazard cascades by damming rivers and initiating catastrophic flash floods and debris flows. Through such long-range effects even unwitnessed landslides occurring in remote areas matter. Critically, insufficient information exists on landslide occurrence and recurrence intervals, and hence on the hazard potential of landslide hazard cascades, as well as possible prediction and prevention measures. This lack of information is mostly due to the remoteness of many mountain regions as well as the complex dynamics of natural hazard cascades even so the hazard posed by landslide dam failures is often orders of magnitudes greater than that of the initial landslide event. In the RiCoLa project, we developed, tested and applied remote sensing and process modeling approaches to detect existing and predict potential landslide dams and landslide-dammed lakes.

The interdisciplinary RiCoLa project combined geomorphology, remote sensing, geoinformatics and hazard research in the frame of the Earth System Science Call of the Austrian Academy of Sciences (ÖAW) and facilitated the collaboration of researchers at the Department of Geography and Geology and the Interfaculty Department of Geoinformatics Z_GIS at the University of Salzburg with colleagues from Taiwan and New Zealand. The central aim of the project was to detect landslide-induced river course changes and lake formation to analyze the role of predisposing (e.g., lithology), preparatory (e.g., climate) and triggering (e.g., earthquakes) factors in the formation of landslide-induced hazard cascades. For this, different tools for the detection and prediction of landslide dams and landslide-dammed lakes on satellite images and digital elevation models had to be developed, tested and applied to different mountain ranges worldwide.

\section{Project execution}

\subsection{Project duration}

The project started on August 1, 2017 and was originally scheduled to end on July 30, 2020. The project was extended twice. Once for 5 months (August 1, 2020, until December 31, 2020), and once for 6 months (January 1, 2021 until June 30, 2021).

The project was prolonged due to certain tasks taking longer than expected and due to the availability of additional funds from outside of the ÖAW, allowing for a cost-neutral continuation of the project. In particular, Günther Prasicek got a postdoc position funded at the University of Lausanne, allowing him to work as the PI of RiCoLa at the University of Salzburg at minimal costs and employing a PhD student, Anne-Laure Argentin, in the RiCoLa project. Further, Anne-Laure Argentin got awarded a 1-year PhD stipend by the University of Salzburg, allowing her to continue her work within the RiCoLa project beyond the originally envisioned employment period. 


\subsection{Important activities}

\subsubsection{Field trip Taiwan}

An important project milestone and dissemination activity was a 10-day research visit in Tainan, Taiwan, in mid-November 2018. During our stay, we jointly organized a workshop and meetings (Figure 1) with our local collaboration partner from Taiwan, the Disaster Prevention Education Center (DPEC), National Cheng Kung University (NCKU). Experts in remote sensing and landslide research from different research and governmental institutions in Taiwan were participating, including experts from the Disaster Prevention Research Center (DPRC) at the NCKU, the National Chi Nan University (NCHU), and the National Space Organization (NSPO). The workshop was used to present the RiCoLa project and the first results as well as to discuss ongoing work and ideas. The feedback gathered was very important for improving our workflows, approaches and results. In addition, further opportunities for collaboration were discussed and evaluated. The Taiwanese colleagues provided valuable information about landslide-dammed lakes in Taiwan and suggested specific locations to be studied.
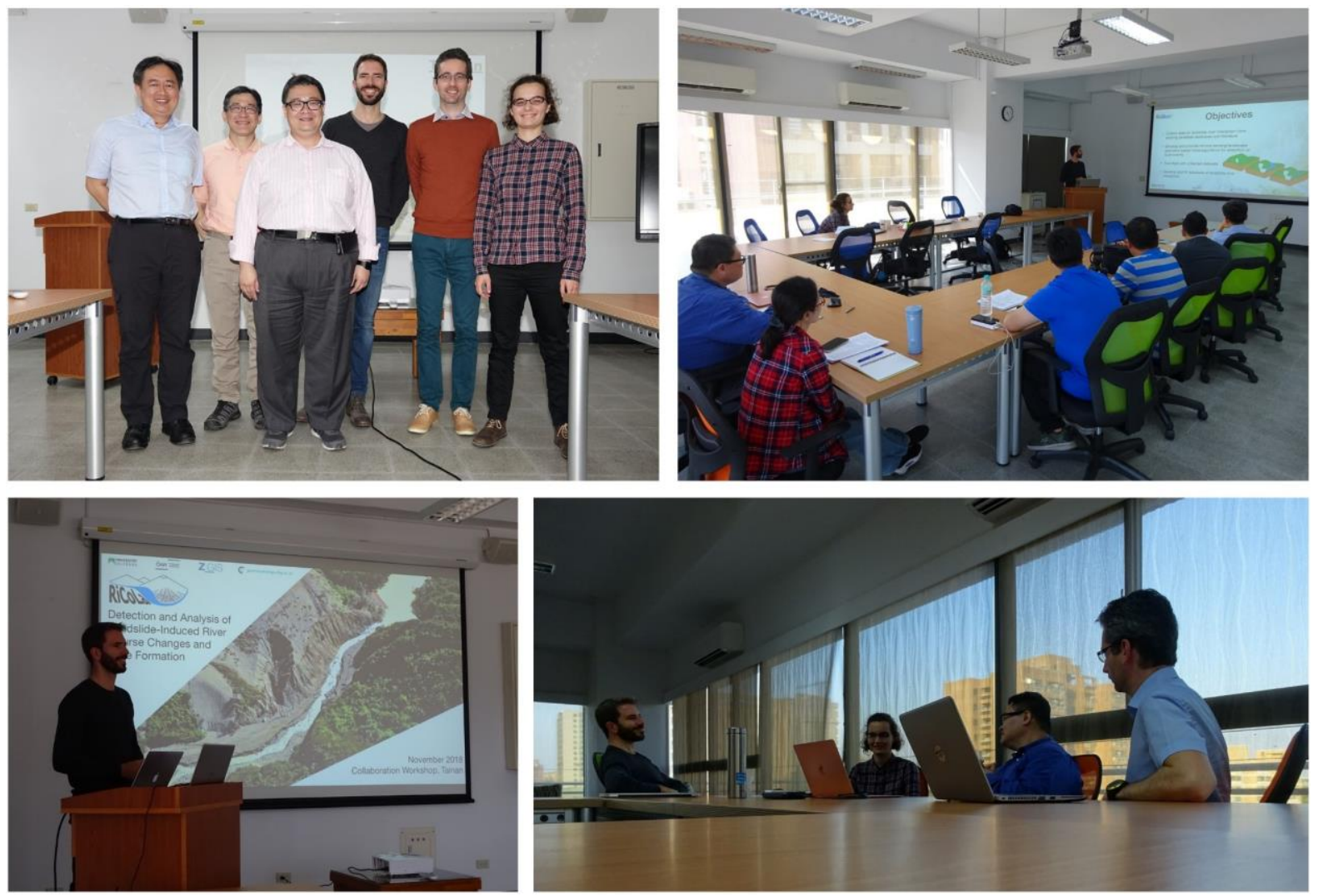

Figure 1: RiCoLa workshop and meetings in Tainan, Taiwan.

In the frame of our visit, we also conducted joint field trips with colleagues from the DPEC and DPRC to selected study areas in Taiwan (Figures 1, 2). This was especially useful for gathering knowledge about the area and the present landslide processes, validating the preliminary mapping results, collecting field reference data (e. g. field photographs, UAV imagery), and identifying mapping errors with the local experts. We visited several landsideaffected areas, particularly such places where landslides dammed rivers and led to the 
creation of a landslide-dammed lake. One field trip was dedicated to visiting the famous Xiaolin landslide as well as the Butangbunasi landslide and the surrounding areas. The information collected in the field and provided by the Taiwanese experts, significantly helped to conduct a detailed study of the Butangbunasi landslide. Another field trip was dedicated to visiting the Caoling landslide, which created a landslide-dammed lake several times in the past.
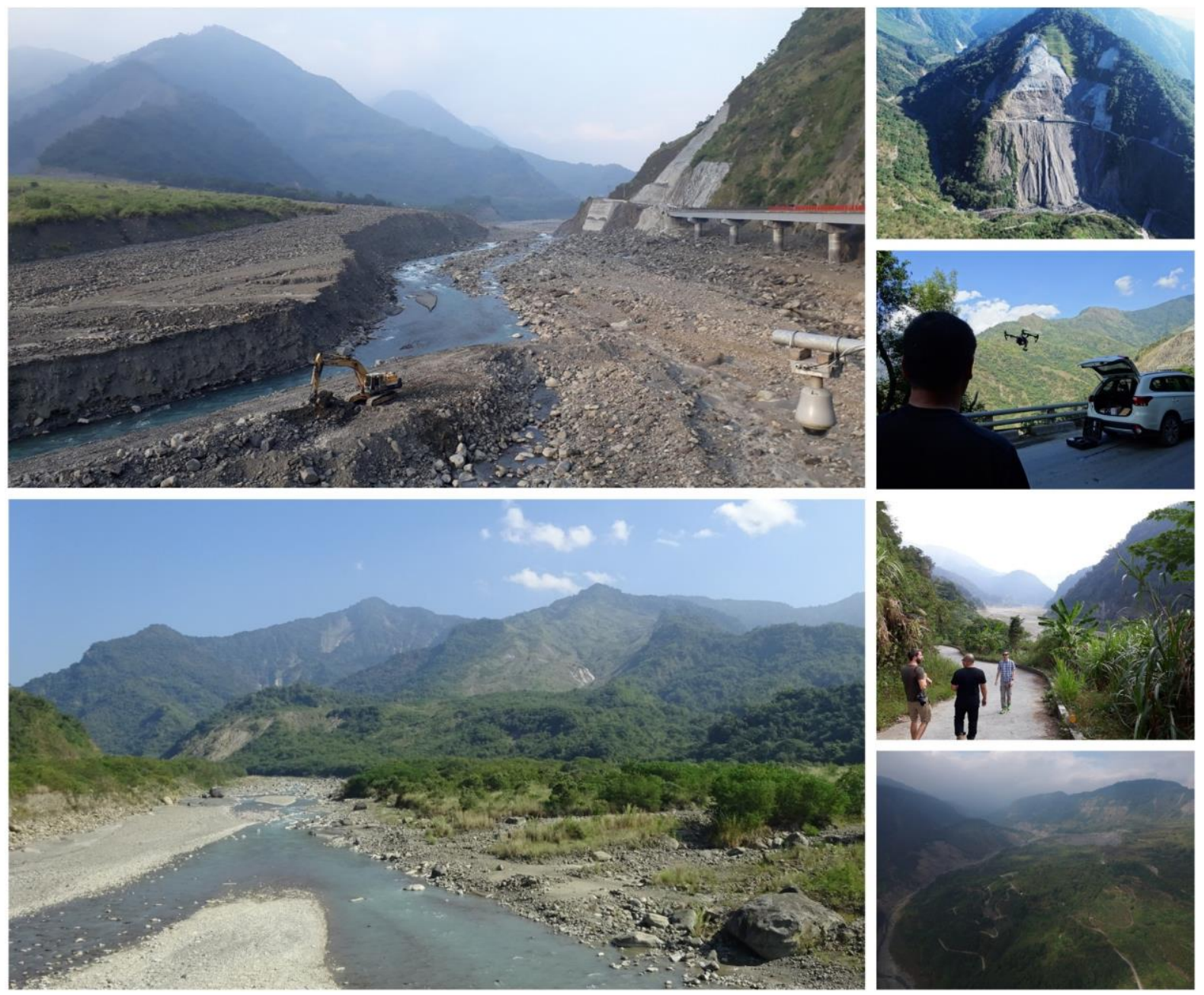

Figure 2: Impressions from the field trips in Taiwan, including construction work at the Butangbunasi debris fan to avoid the damming of the river (top left), the Xiaolin landslide (bottom left) and the Caoling landslide (bottom right). Field photographs and UAV images were taken by A.-L. Argentin, D. Hölbling and C.-Y. Tsui in November 2018.

\subsubsection{Field trips New Zealand}

Within the scope of her work at the PhD studies in the frame of the RiCoLa project, AnneLaure Argentin visited the Canterbury University in New Zealand for 6 months, from 24th November 2018 to 24th May 2019. She worked with the local experts on landscaape geometry-based landslide dam detection methods, went on field trips to study the morphology of landslide dams (Figure 3), attended the 18th Australia New Zealand Geomorphology Group conference and a workshop dedicated to the study of landslide dams in Kaikoura. 

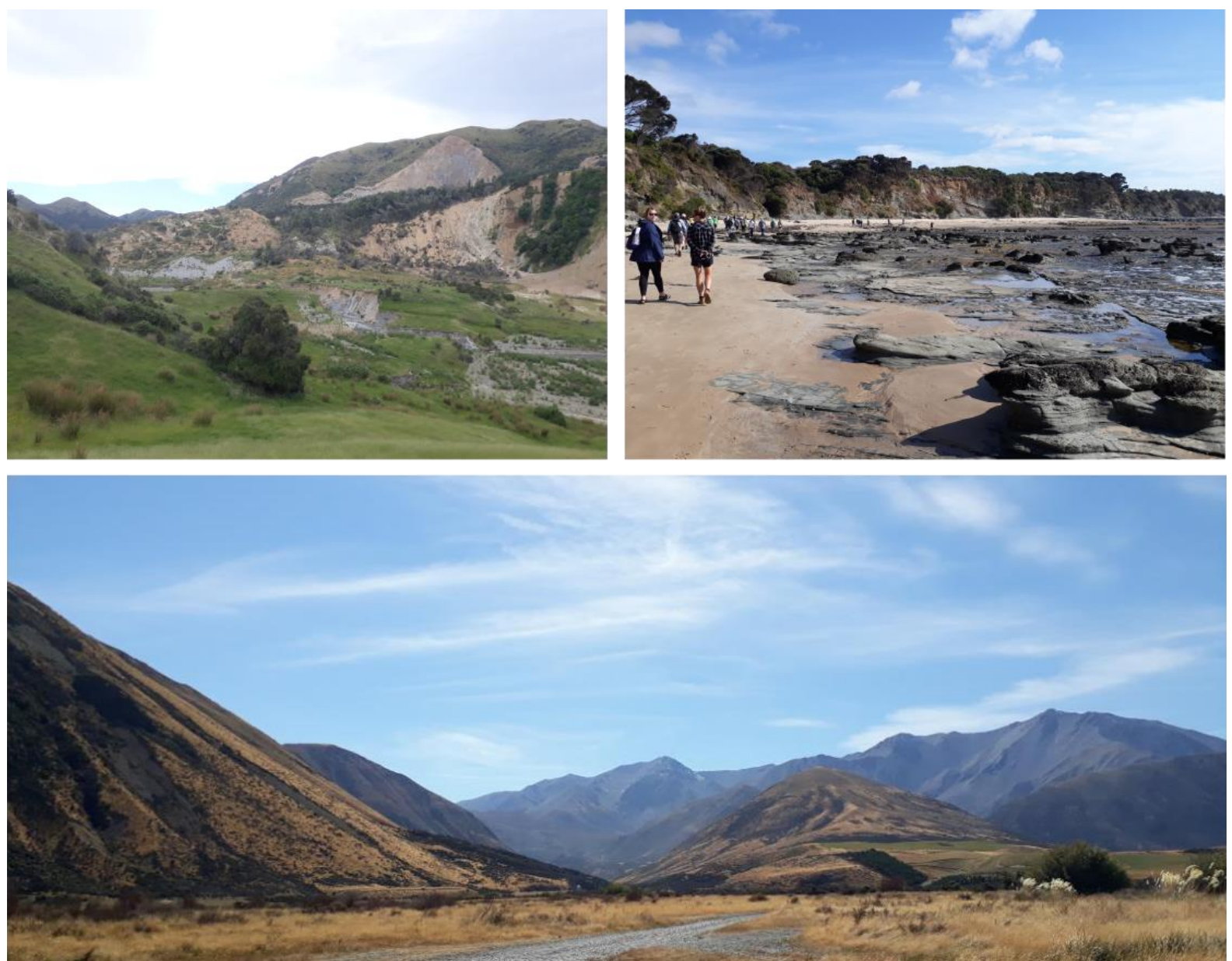

Figure 3: Impressions from the field trips in New Zealand. The Leader dam (top left), triggered by the Kaikoura earthquake, has been eroded by the river. The landslide pushed the river out of its normal bed and the water incised into old terraces. Field trip of the ANZGG conference (top right) focusing on coastal and fluvial geomorphology. Remnants of the Coleridge landslide dam (bottom) with landslide deposits protruding from the mountain with a smaller slope, and a very dark green vegetation cover. Field photographs taken by A.-L. Argentin.

During another trip to New Zealand, Daniel Hölbling organized meetings with collaborators and local experts from Manaaki Whenua - Landcare Research (MWLR) to discuss how the methods developed in RiCoLa could be applied to the study sites in New Zealand and which challenges and opportunities are present. Moreover, during a field visit he gained new knowledge about the local environmental and geomorphological conditions as well as the impact of landslides, in particular earthflows, on the local drainage system.

\section{Most important results}

\subsection{In a nutshell}

- We analyzed the relationship between the area of the Butangbunasi landslide and lake, Tawian, and the occurrence of typhoons.

- We automatically detected lakes and damming landslides on Landsat satellite images of Taiwan. 
- We traced landslide area and dammed lake changes in New Zealand through satellite image time series and categorized lakes based on temporal change patterns.

- We automatically detected landslide dam locations on digital elevation models (DEMs).

- We simulated potential landslide dams and lakes across Austria.

- We determined the scaling of landslide dam and lake area in different mountain ranges around the globe.

- We modeled the landslide and the formation of the dam that impounded lake Hintersee, Bavaria.

- We investigated landslide-induced geomorphological changes and lake formation on Sentinel-1 and Sentinel-2 satellite data.

\subsection{Mapping and monitoring of river-damming landslides on satellite images}

For mapping and monitoring of river-damming landslides on satellite images we used objectbased image analysis (OBIA), demonstrated by two case studies as described in the following. OBIA provides a suitable methodological framework for efficient landslide mapping, as well as landslide change analysis (Lu et al., 2011; Hölbling et al., 2012). By working on the objectlevel instead of the pixel-level, OBIA allows considering spectral, spatial, textural, morphometric and hierarchical properties for the classification of landslides (Martha et al., 2010; Hölbling et al., 2015). Moreover, it is argued that using OBIA yields better classification accuracies than pixel-based classifications (Martha et al., 2010; Moosavi et al., 2014; Keyport et al., 2018). Several studies employed OBIA for landslide mapping and landslide change detection in Taiwan (Lahousse et al., 2011, Eisank et al., 2014; Rau et al., 2014; Hölbling et al., 2015; Plank et al., 2015), but none of them used time series of images for investigating the evolution and reactivation of an active large landslide or aimed to detect river-damming landslides.

\subsubsection{Analyzing the evolution of the Butangbunasi landslide}

For mapping and monitoring the evolution of a large river-damming landslide in south-central Taiwan, i.e., the Butangbunasi landslide (Figure 4), we developed an object-based image analysis (OBIA) approach based on a time series of Landsat imagery. Moreover, we analyzed the potential relationship between landslide extension or re-activation with respect to heavy rainfall events during typhoons. Reactivation and extension of this major landslide have been taking place since the 1980 s and have been resulting in repeated sediment delivery to the Laonong River, especially during torrential rainfall brought by typhoons. A landslide-dammed lake was created several times in the past. Better knowledge about the evolution of landslides, their triggering factor and the impact of landslides on rivers and on the downstream area is of high importance for disaster mitigation. In November 2018, we visited the Butangbunasi landslide and collected important information that helped to perform this 
study. Intermediate results have been published in Hölbling et al. (2019) and final research outcomes in Hölbling et al. (2020). In the following, the main findings of this case study are summarized.
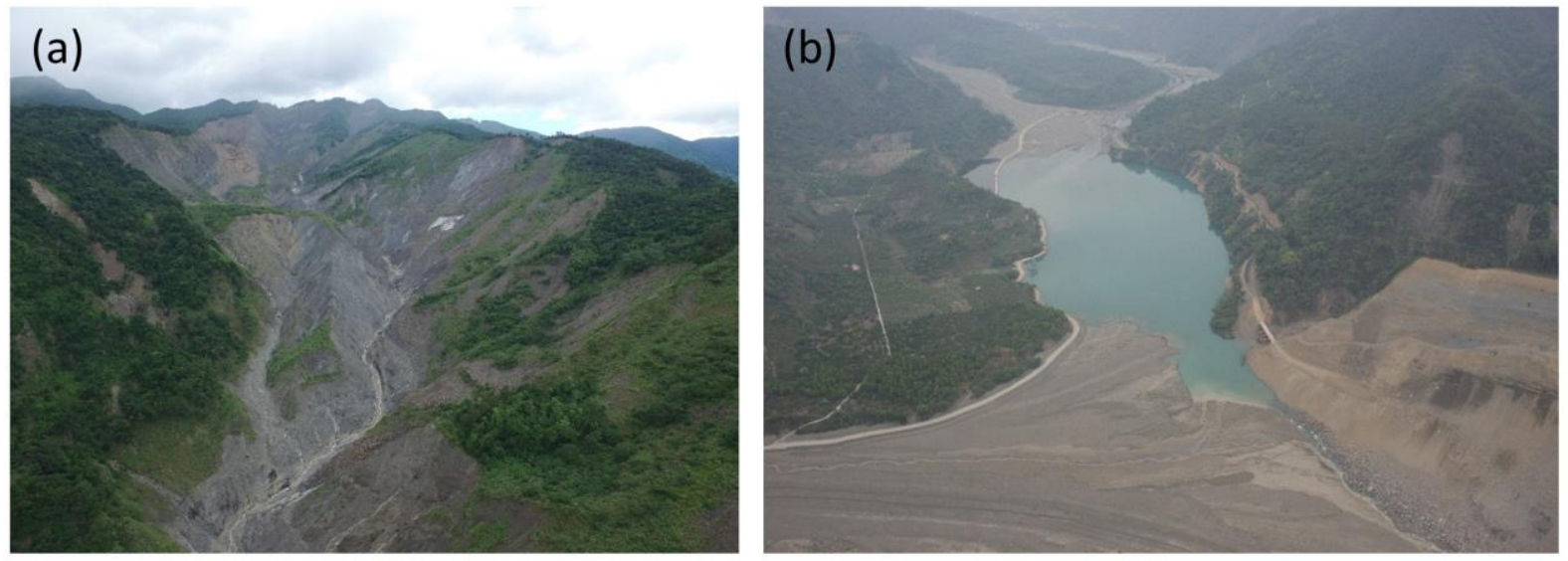

(c)

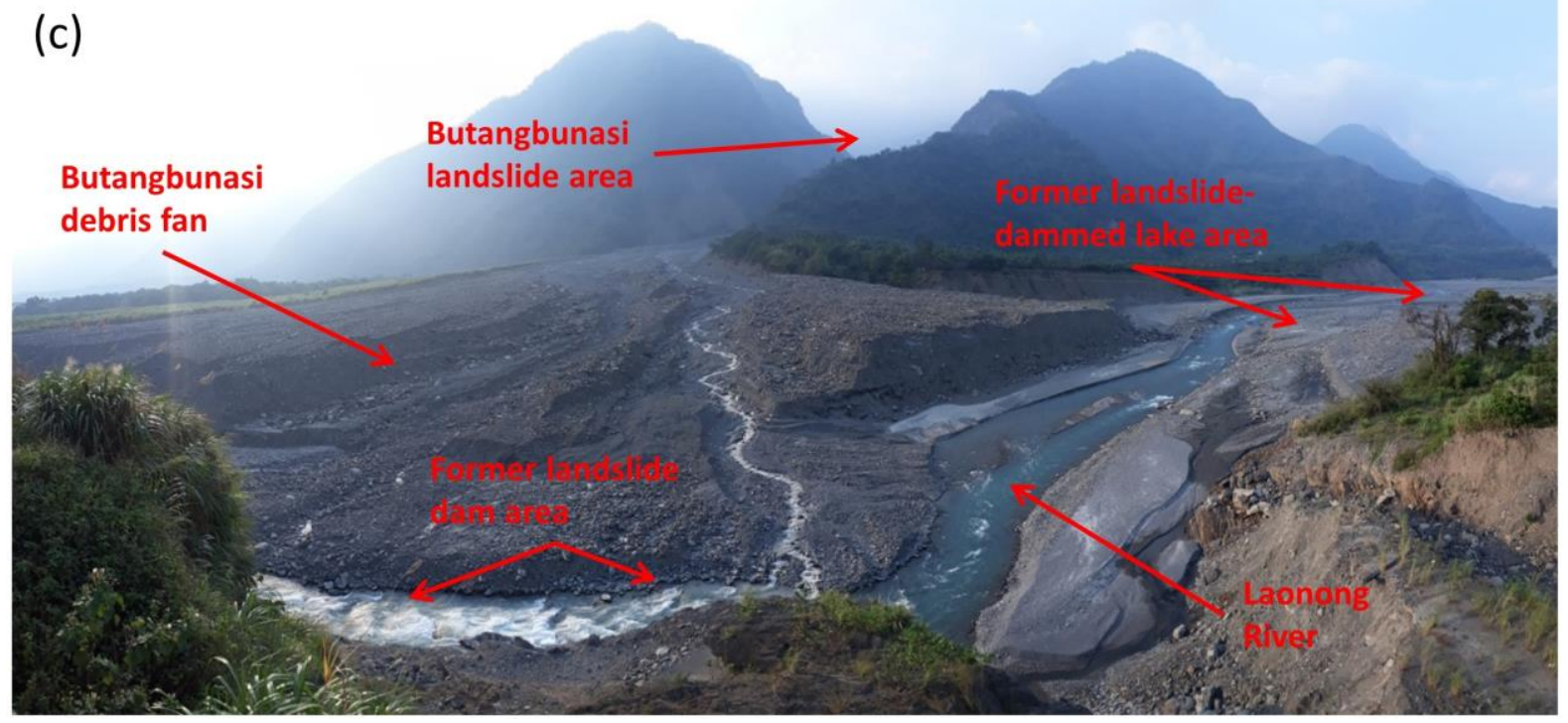

Figure 4: The Butangbunasi landslide area. (a) Unmanned aerial vehicle (UAV) image of the upper part of the Butangbunasi landslide from June 2017. (b) UAV image of the temporary landslide-dammed lake at Butangbunasi and parts of the debris fan from April 2011. (c) Photograph of the Butangbunasi landslide from November 2018. The photograph was taken from the Laonong river valley looking towards Butangbunasi; the actual landslide area is further up the tributary. The Butangbunasi debris fan, the former lake area, and the former landslide-dam area are indicated. From Hölbling et al. (2020).

\subsubsection{Semi-automated object-based landslide and lake mapping}

We used time series of optical satellite data from Landsat 5, Landsat 7 and Landsat 8 with $30 \mathrm{~m}$ spatial resolution. Overall, 20 Landsat images from 1984 to 2018 were selected to semiautomatically map the evolution of the Butangbunasi landslide. In particular, we used the first cloud-free image available after a typhoon or tropical storm event that shows a change in the landslide area compared to pre-event images.

We defined a set of knowledge-based classification rules for the OBIA mapping of the landslide area per image, starting with the Landsat 5 image from 1984. The analysis was done 
using the eCognition (Trimble) software. Since images from 20 different points in time were used, efforts were made to design a transferable classification approach that could be applied to all images without or with only minor adaptations of the classification thresholds. Primarily, we used the normalized difference vegetation index (NDVI), the modified soil-adjusted vegetation index (MSAVI), and a brightness layer for classification of segmentation-derived image objects. The absence of vegetation was the main indication for mapping the landslide area, which leads to a distinctive spectral contrast between the landslide-affected area and its surroundings, especially in densely vegetated regions (Rau et al., 2014; Behling et al., 2014; Hölbling et al., 2015). By using the mentioned spectral indices, we were able to identify these changes in land cover and to develop a transferable object-based time series analysis classification scheme, which shows a high level of automation. Only minor adaptations in the classification rules were needed for one image that was taken at a different season and for applying the classification to Landsat 7 and Landsat 8. This approach enabled us to detect and map the landslide area and its changes for each image. Moreover, we identified a landslidedammed lake on several of the Landsat images with our semi-automated approach. The classification accuracy, i.e. producer's accuracy and user's accuracy, was assessed by comparing the OBIA results to results from visual image interpretation.

\subsubsection{Correlation between the change in landslide area and rainfall during typhoons}

We obtained the hurricane/typhoon best-track position and intensity from the International Best Track Archive for Climate Stewardship (IBTrACS) data repository to extract the spatial information corresponding to 19 typhoon events that had an impact on the landslide area or had a Saffir-Simpson hurricane wind scale (SSHWS) category three (H3) or higher within a 100 $\mathrm{km}$ radius from the Butangbunasi landslide. Rainfall data were obtained from Taiwan's Central Weather Bureau (CWB). CWB provides station weather data, which includes hourly precipitation for each typhoon event for all the automatic rain gauge stations in Taiwan. For this study, we used the three closest stations to the Butangbunasi landslide. However, since the entire study period was not covered by the CWB rain gauge station data, we also acquired data from the Climate Hazards Group Infrared Precipitation with Station (CHIRPS) dataset.

We extracted daily precipitation from the CHIRPS data for the date when the typhoon was closest to the landslide. Hourly precipitation from the CWB rain gauge station data allowed us to identify rainfall events during the typhoons. For each rainfall event, we calculated the duration, cumulative rainfall and intensity. The rainfall event with the highest duration and intensity within each typhoon event was selected for further analysis. Finally, we tested for rank correlation after Spearman between the landslide area change and the derived rainfall parameters for each CWB rain gauge station and the daily precipitation derived from the CHIRPS data.

\subsubsection{Mapping results and relation between landslide evolution and rainfall}

The OBIA landslide mapping results for each of the Landsat images are shown in Figure 5. Next to the Butangbunasi landslide area, we could detect a temporary landslide-dammed lake at the confluence of the Butangbunasi tributary with the Laonong River on six images. The comparison of the semi-automated OBIA results with the results from visual interpretation 


\section{RiColl Final Project Report}

revealed for the landslide area producer's accuracies between $82 \%$ and $89 \%$, and user's accuracies between $84 \%$ and $95 \%$. For the landslide-dammed lake, we achieved lower accuracies, i.e. producer's accuracies between $71 \%$ and $79 \%$ and user's accuracies between $62 \%$ and $81 \%$. The lower accuracies for the lake result from classification uncertainties associated with mixed objects, partly shallow water areas with high sediment load or wet areas in the riverbed. 

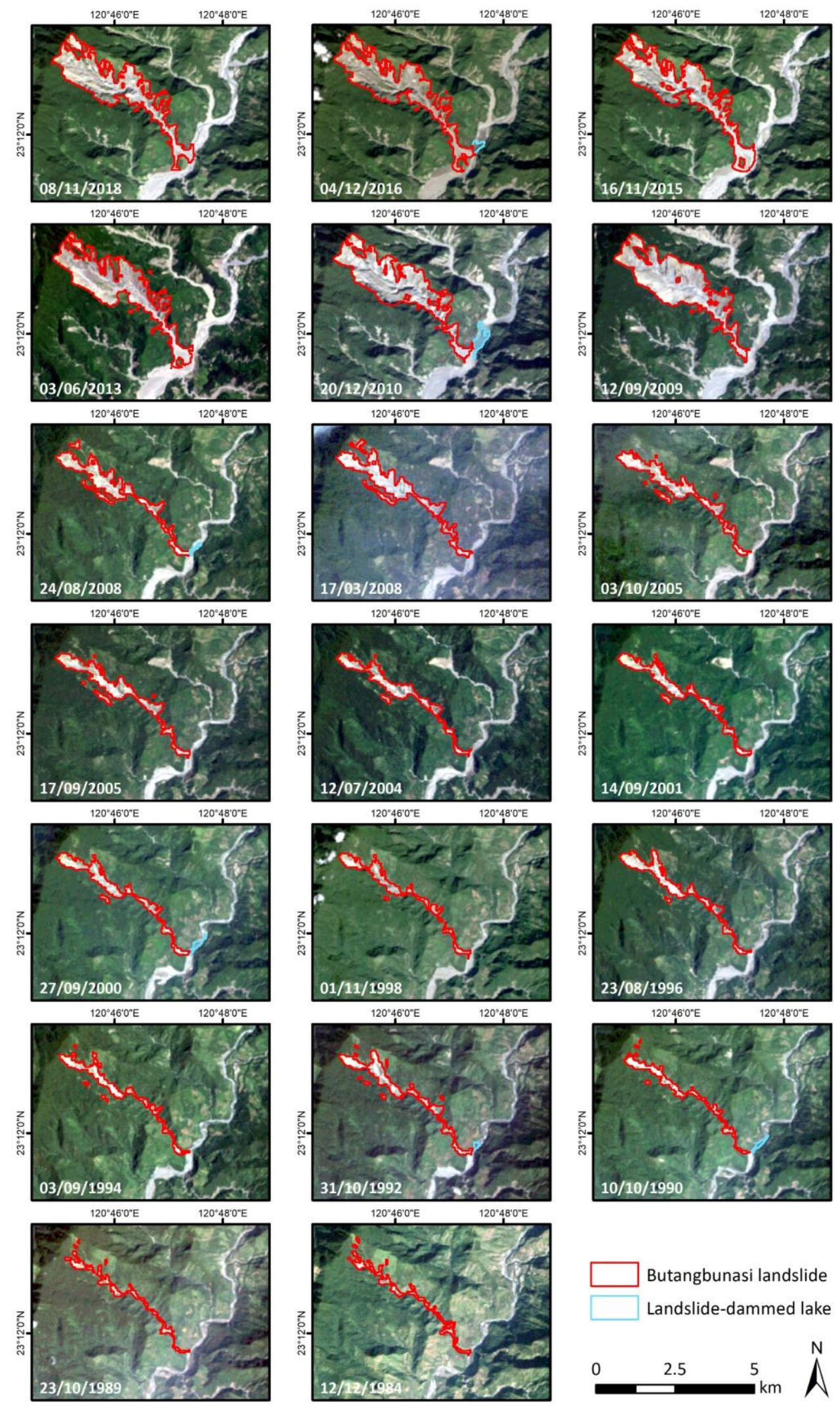

Figure 5: OBIA mapping results for the Butangbunasi landslides using Landsat images from 1984 to 2018. Additionally, a landslide-dammed lake was detected on six of the images (2016, 2010, August 2008, 2000, 1992 and 1990). From Hölbling et al. (2020). 
To assess the influence of typhoon events on landslide evolution, each typhoon was linked to the respective Landsat image date when the OBIA landslide mapping was performed. Figure 6 shows the time series where landslide area evolution was tracked along with the preceding typhoon events. An abrupt increase in landslide area was identified after typhoon Morakot in 2009, while a steady or even slightly decreasing trend can be observed for the other typhoons.

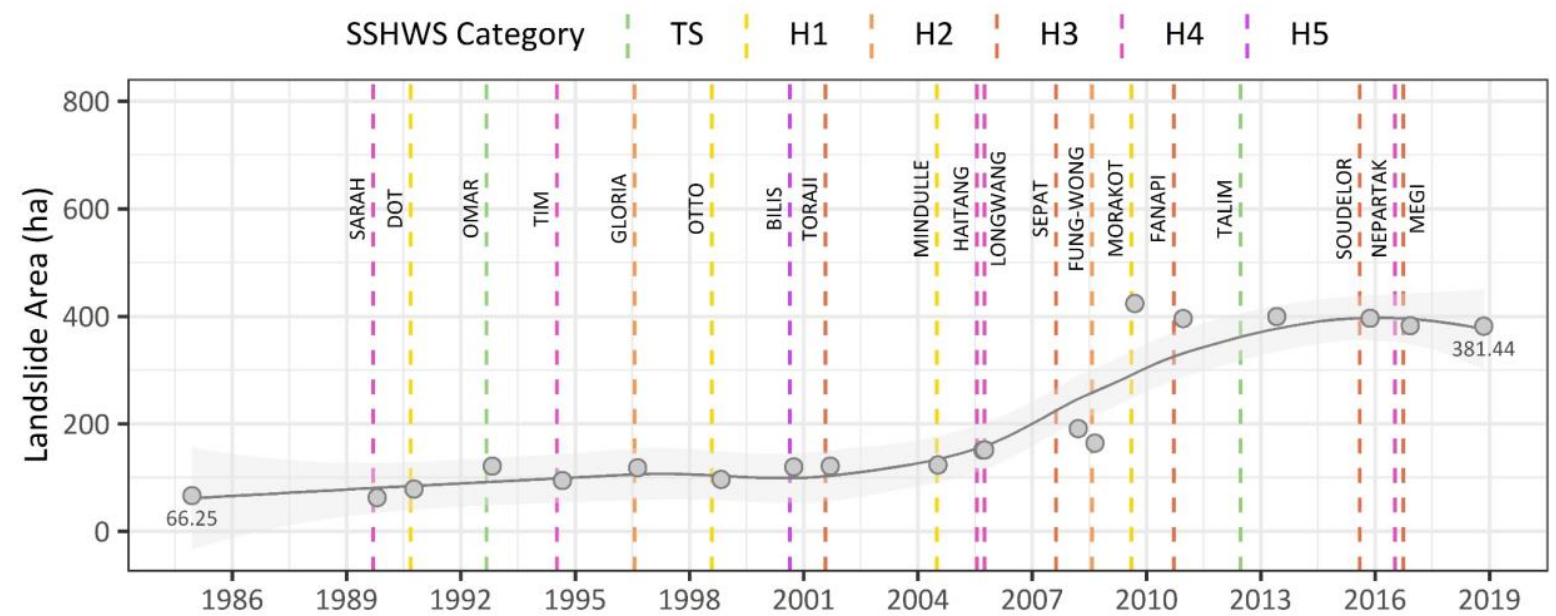

Figure 6: Butangbunasi landslide area evolution and the dates of each typhoon event. The SSHWS category corresponds to the maximum category reached by the typhoon when crossing Taiwan. A locally estimated scatterplot smoothing (LOESS) curve (confidence interval 95\%) is fitted to the time series for illustration purposes. From Hölbling et al. (2020).

Daily precipitation data from CHIRPS for the date when a typhoon passed over Taiwan were correlated with the landslide area change for the typhoon events. The results show that there was not enough evidence of a significant correlation between the variables. Moreover, we tested for correlations between the landslide area change and the cumulative rainfall, duration and mean intensity of the rainfall events during typhoon events for the three available CWB stations (Meishan, Fuxing, Xiaoguanshan). The rainfall parameters per CWB station were plotted against the landslide area change and the resulting Spearman's rank correlation coefficients (Figure 7). For the Fuxing and Xiaoguanshan stations, moderate positive correlations were found at a $90 \%$ confidence level between the change in the landslide area and the duration of the heavy rainfall event. 

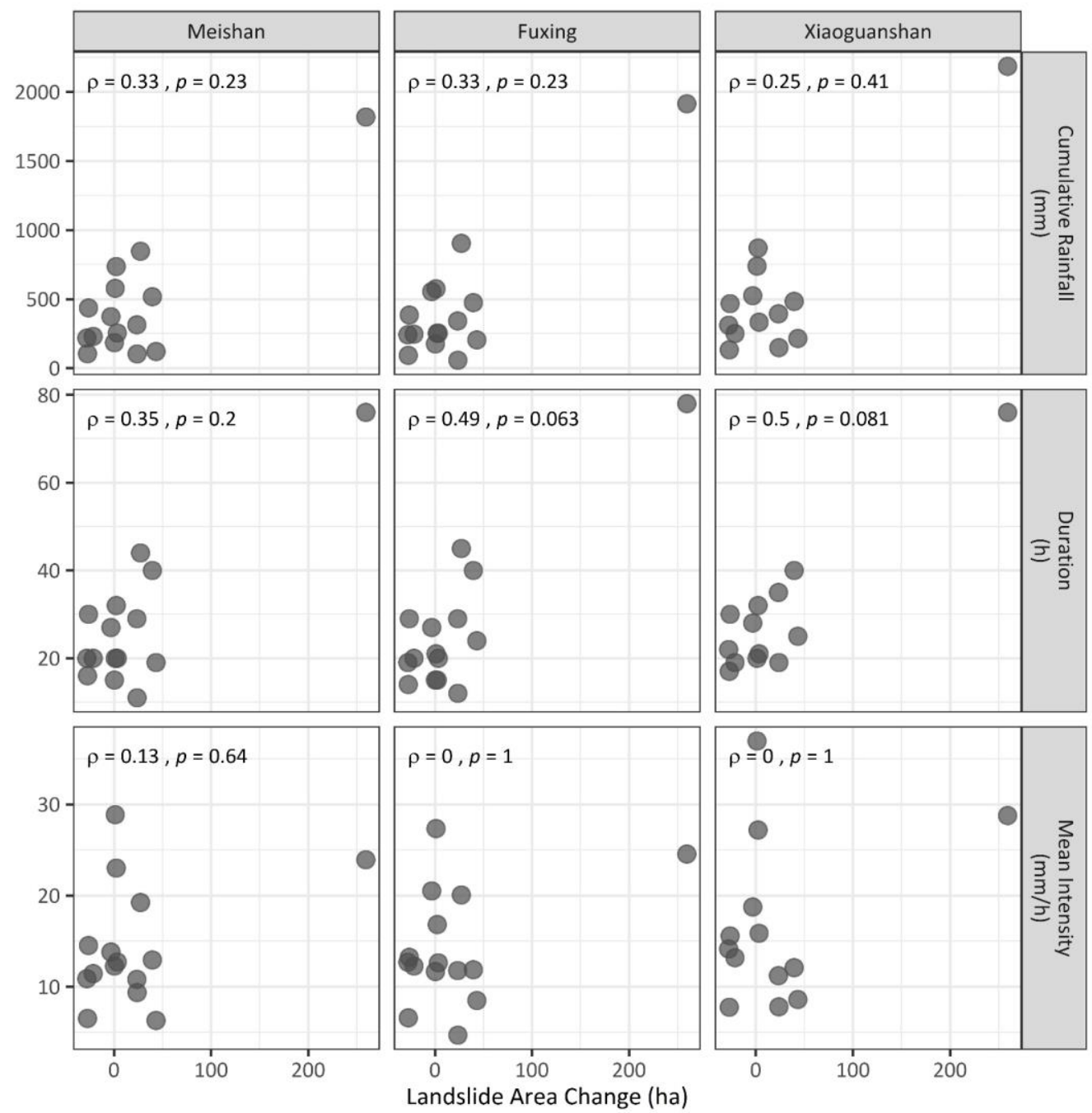

Figure 7: Spearman correlation results between the Butangbunasi landslide area change and rainfall event parameters calculated for three CWB stations for selected typhoon events. From Hölbling et al. (2020).

Our results demonstrate that the proposed approach is suitable to semi-automatically map the evolution of landslides with time series of satellite images. Moreover, we could identify landslide-dammed lakes on some of the images and by that reveal new knowledge about landslide-river interaction. Our results on the analysis of the relationship of landslide rainfall during typhoons indicate that the duration of the heavy rainfall event is the main parameter linked to the landslide area change, while cumulative rainfall and mean intensity did not show significant correlations with the extension of the landslide.

Rainfall-induced landslides are among the most dangerous natural hazards in Taiwan, putting people and infrastructure at risk. While our results did not indicate a direct relationship between the extension of the Butangbunasi landslide and the strength of the typhoon event, it became evident that also comparatively small typhoons or tropical storms caused landslide reactivation. Knowledge about the evolution and reactivation of large landslides and the recurring impact on rivers and downstream areas is of high importance for disaster mitigation. 


\subsubsection{Mapping landslides that created landslide dams and monitoring of the dammed} lakes in Taiwan using OBIA

\subsubsection{Detection of landslide-dammed lakes and triggering landslides based on Landsat}

We used OBIA for the detection of landslide-dammed lakes and triggering landslides. For a first study (Friedl et al., 2018), we selected a sub-region of the Central Mountain Range of Southern Taiwan, where landslide-induced lake formation was observed after Typhoon Morakot in 2009. The semi-automated analysis was based on a post-event Landsat-5 image acquired on 12/09/2009 and the SRTM DEM including derived products with $30 \mathrm{~m}$ spatial resolution. We derived the Normalized Difference Water Index (NDWI), the NDVI, and a brightness layer from the Landsat image, and flow accumulation and slope derived from the DEM. The spectral indices were considered for image segmentation. By using a combination of the spectral, spatial, morphological and contextual characteristics we could detect the existing landslides and lakes and by establishing a spatial relation we semi-automatically identified the potentially dam-causing landslides. The classification result is shown in Figure 8 , a detailed view of the indicated subsets is provided in Figure 9.

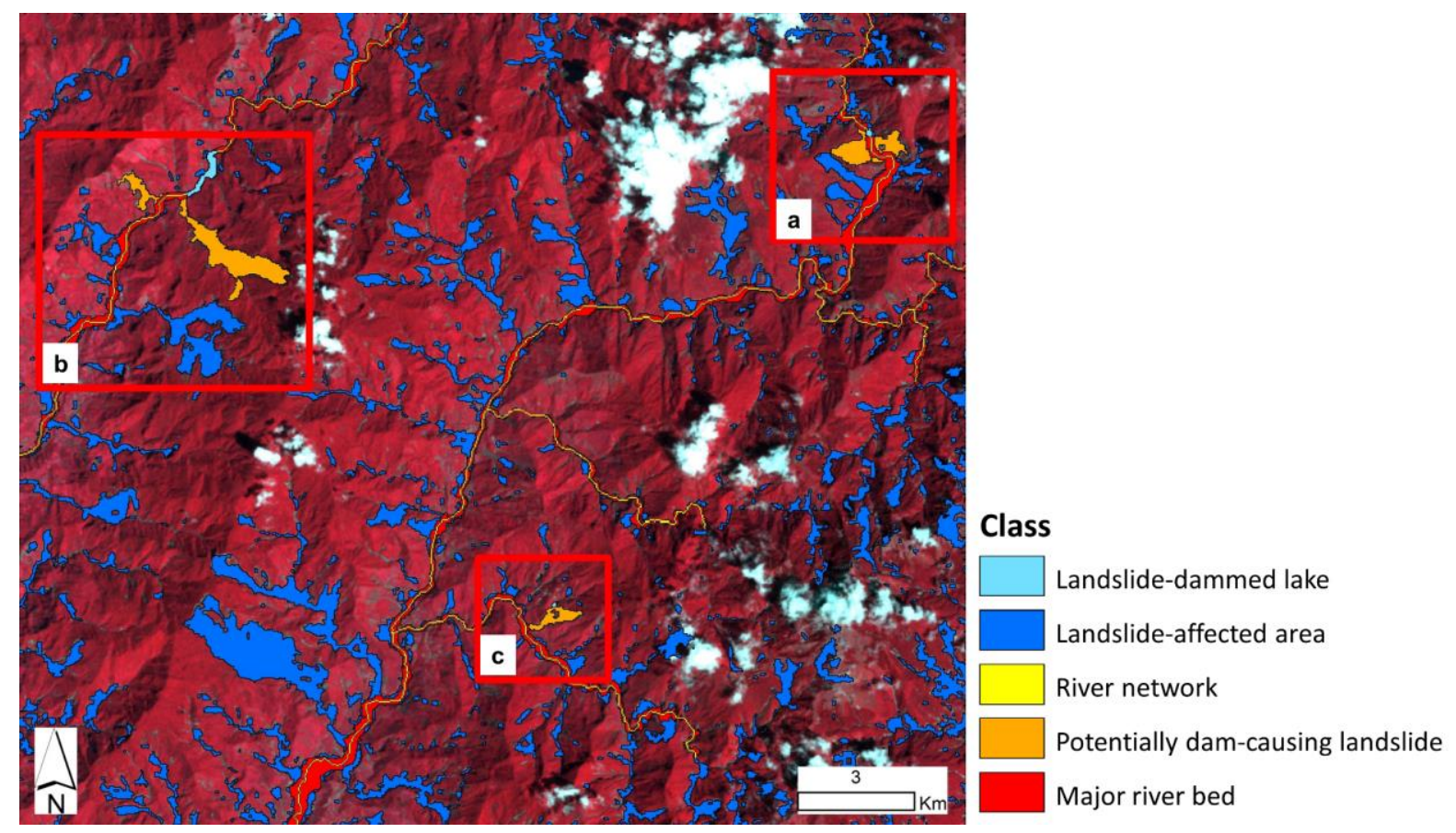

Figure 8: Classification results using OBIA, based on a Landsat image (12/09/2009) and DEM products derived from the SRTM. The red rectangles $(a, b$, and $c)$ indicate the location of the detected landslide-dammed lakes and the triggering landslides (see Figure 9). 


\section{RiCold $\Rightarrow$ Final Project Report}
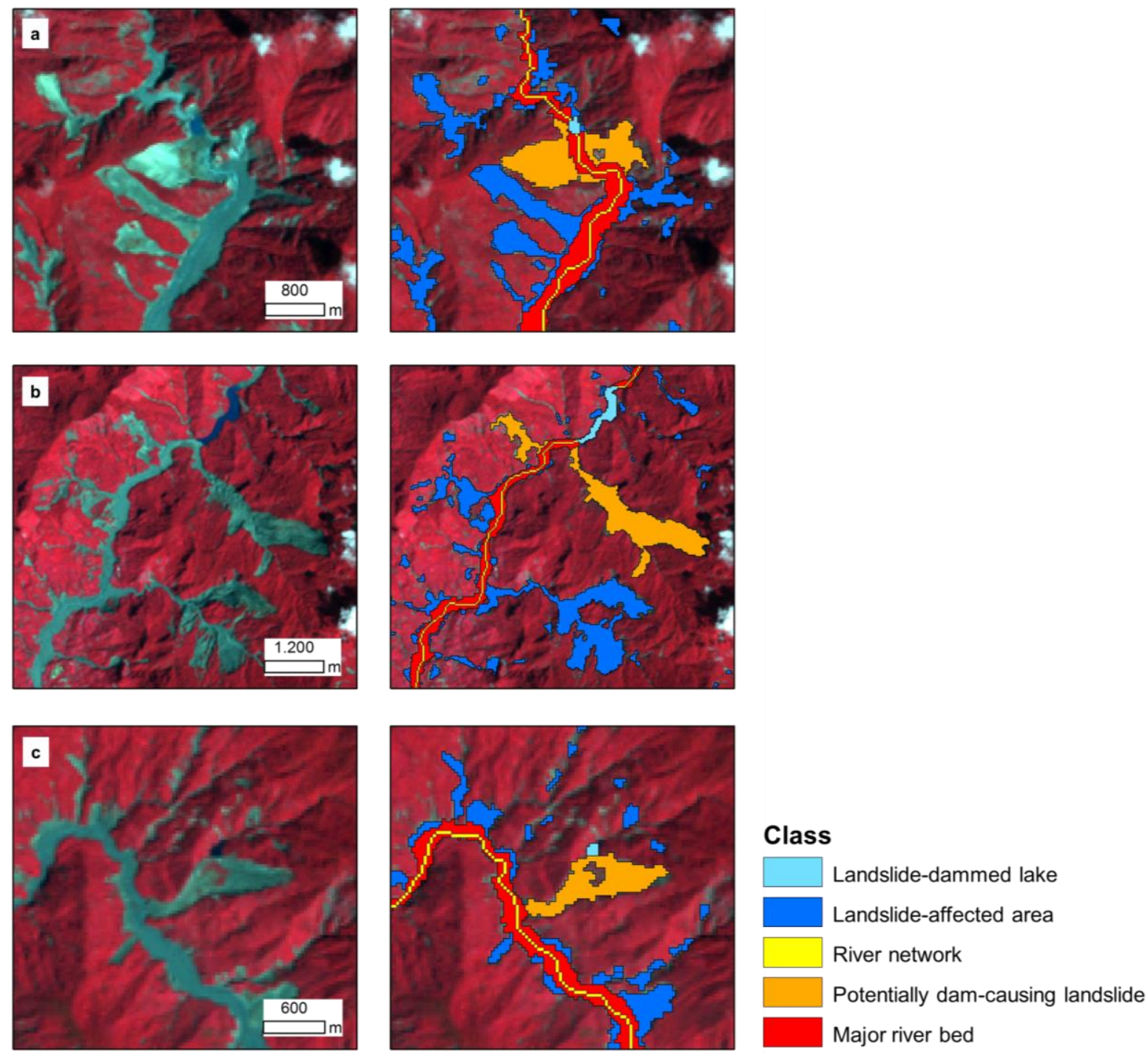

Figure 9: Detailed view of the classification results (right) for the three subsets $(a, b, c)$ indicated in Figure 8 , and original Landsat-5 image from 12/09/2009 in false-colour composition (left).

The largest landslide dam detected measures 24.12 ha and the largest triggering landslide is 161.01 ha in size. Table 1 summarized the findings for the three subsets.

Table 1: the results of area (ha) for the landslide-dammed lake and the triggering landslides, for the three subsets, a, b, and c. The mean slope $\left({ }^{\circ}\right)$ in which the classes were detected are presented.

\begin{tabular}{|l|c|c|c|c|c|}
\hline & Class name & \multicolumn{2}{|c|}{ Area (ha) } & \multicolumn{2}{c|}{ Mean slope $\left(^{\circ}\right.$ ) } \\
\hline \multirow{3}{*}{ Subset (a) } & Landslide-dammed lake & \multicolumn{2}{|c|}{2.88} & \multicolumn{2}{c|}{34.30} \\
\cline { 2 - 6 } & Triggering landslide $\left(^{*}\right)$ & 52.83 & 31.14 & 36.92 & 45.98 \\
\hline \multirow{3}{*}{ Subset (b) } & Landslide-dammed lake & \multicolumn{2}{|c|}{24.12} & \multicolumn{2}{c|}{22.69} \\
\cline { 2 - 6 } & Triggering landslide (*) & 161.01 & 32.85 & 29.71 & 32.02 \\
\hline \multirow{3}{*}{ Subset (c) } & Landslide-dammed lake & \multicolumn{2}{|c|}{1.35} & \multicolumn{2}{c|}{24.33} \\
\cline { 2 - 6 } & Triggering landslide & \multicolumn{2}{|c|}{34.29} & \multicolumn{2}{c|}{30.20} \\
\hline
\end{tabular}

(*) Two landslides were identified as potential triggers 
Based on these findings, we further developed the classification routine so that it could be applied to monitor the evolution of landslide-dammed lakes with satellite image time series. Moreover, an inventory of landslide-induced lakes and triggering landslides and a better understanding of landslide-river interaction are crucial to assess and predict natural hazards and hazard cascades.

\subsubsection{Detecting lake-triggering landslides and monitoring the evolution of dammed lakes using multi-temporal Landsat imagery}

Following the previous study (Friedl et al., 2018), we further developed the approach towards a change detection approach for monitoring the evolution of landslide-dammed lakes and detecting triggering landslides using multi-temporal Landsat imagery in the northern part of the Kaohsiung county in south-central Taiwan (Dabiri et al., 2019). We used multi-temporal Landsat imagery from 30/10/2009, 20/10/2010, and 06/02/2011, and the ALOS PALSAR DEM data (C JAXA) with 12 spatial resolutions. Figure 10 shows the overall methodological workflow. In the first step, we created a DEM mosaic that covers the whole study area, and then we derived surface parameters, such as slope, aspect, and curvature, and hydrological related parameters, such as flow-direction, flow-accumulation, and stream order.

Next, we pre-processed and calibrated the Landsat images and derived spectral indices (NDWI, NDVI, brightness) which served as additional information layers during classification. For the rule-based classification in OBIA, we used the eCognition (Trimble Geospatial) software and specific classification criteria (Figure 10). The assumption for defining landslides that led to river damming was that the nearest landslide downstream of a detected lake had the highest probability to create the landslide dam.

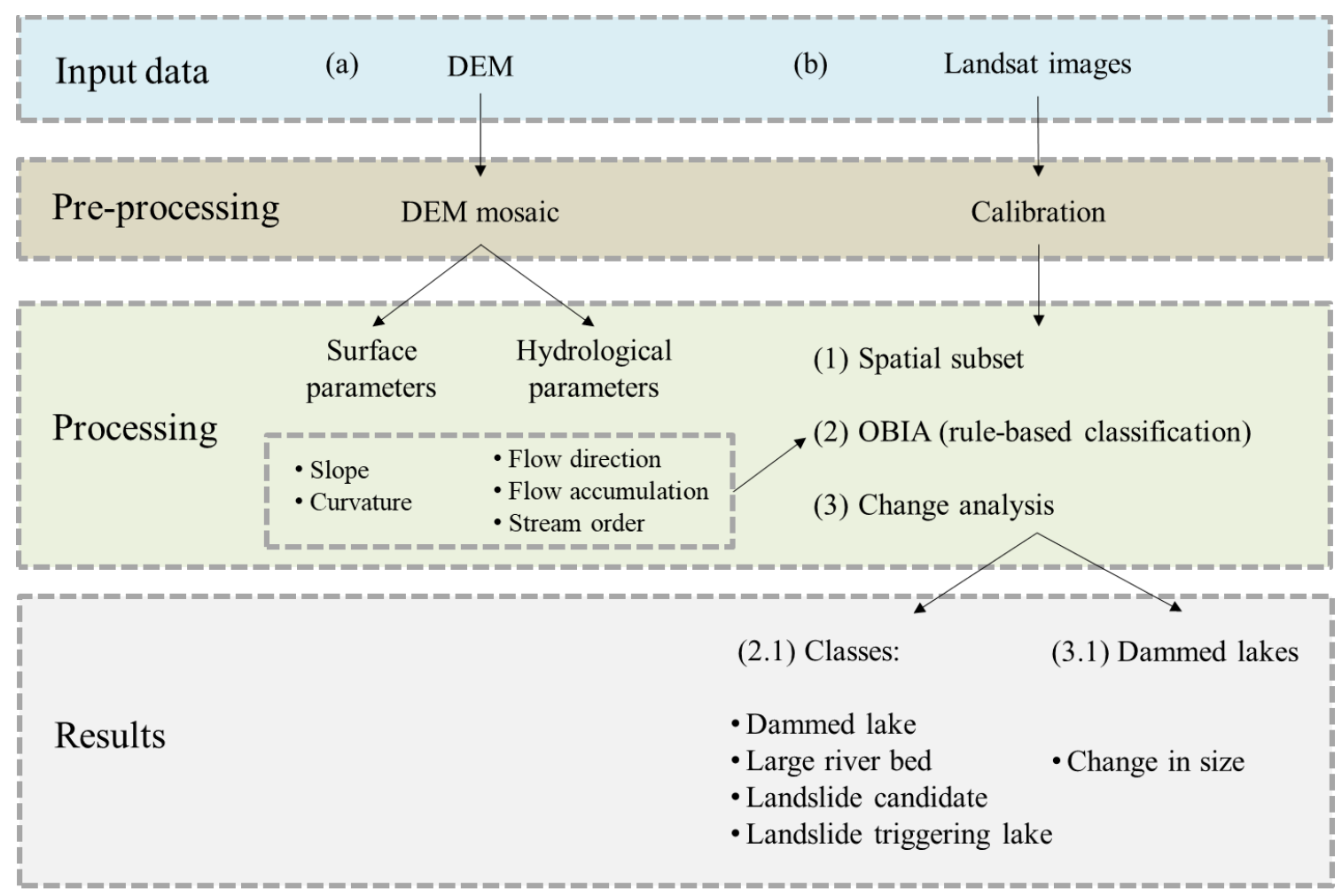


Figure 10: Overall methodological workflow for monitoring the evolution of landslide-dammed lakes and detecting triggering landslides. The input data included (a) DEM derived from the ALOS PALSAR, and (b) Landsat images from three different dates. The pre-processing of the images included creating the DEM mosaic for the study area and Landsat image calibration. Several surface (e.g., slope and curvature), and hydrological (e.g., flow direction, flow) parameters were derived from the DEM. OBIA was used for data integration and classification. Modified after Dabiri et al. (2019).

Figure 11 presents the classification results. For validation of the results, we compared them to a reference dataset of dammed lakes and triggering landslides, created based on literature and visual interpretation. For the year 2009, we correctly extracted two landslide-dammed lakes out of three, for the year 2010 four landslide-dammed lakes out of five, and for the year 2011 three landslide-dammed lakes out of four. As for the semi-automatically detected laketriggering landslides, apart from one misclassification in the year 2010, all other landslides that led to the formation of a dammed lake were correctly detected. However, the delineation of single landslides was challenging and not always appropriate. The difficulty to delineate single landslides as single objects semi-automatically is a problem with OBIA (Hölbling et al., 2016), which needs further investigation in future.

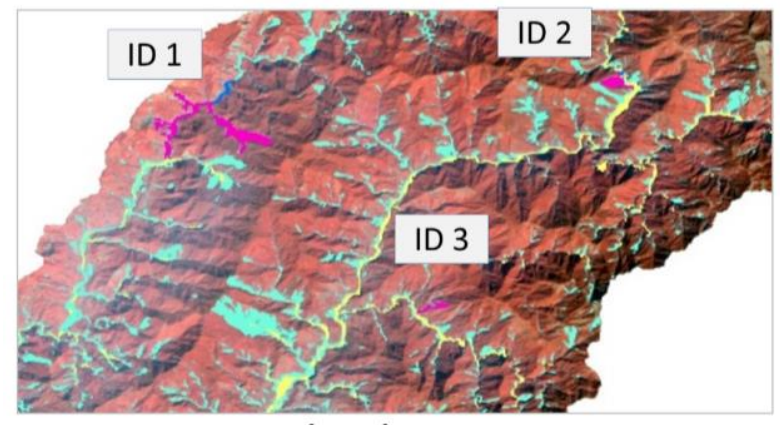

$30 / 10 / 2009$

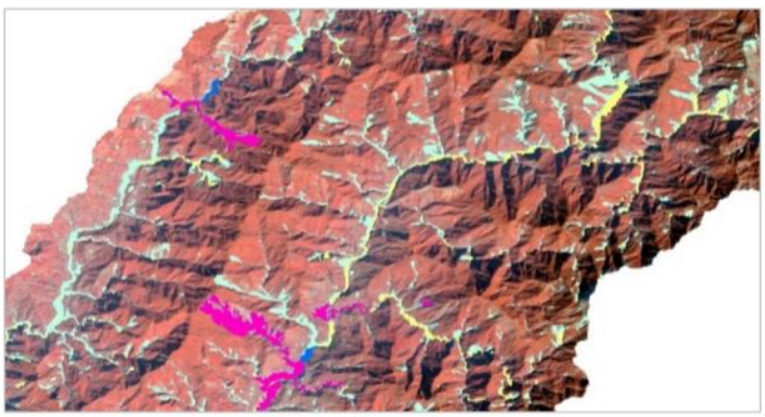

$06 / 02 / 2011$

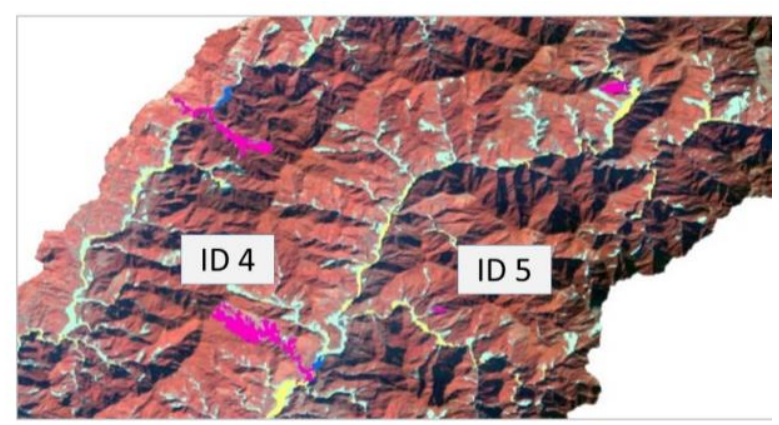

$20 / 12 / 2010$

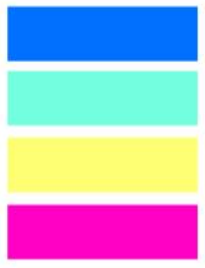

Lake

Landslide candidate

Large river bed

Triggering landslide

Figure 11: Illustration of the classification results for the Landsat images from 2009/10/30, 2010/12/20, and 2011/02/06. The IDs indicate identified landslide-dammed lakes and on which image they have first been detected; see also Figure 11). Modified after Dabiri et al. (2019).

Figure 12 shows the trend in area changes for each landslide-dammed lake. The area of the landslide-dammed lakes ID-1 and ID-4 increased. All the other landslide-dammed lakes showed a decline in their area during the three investigated years. 


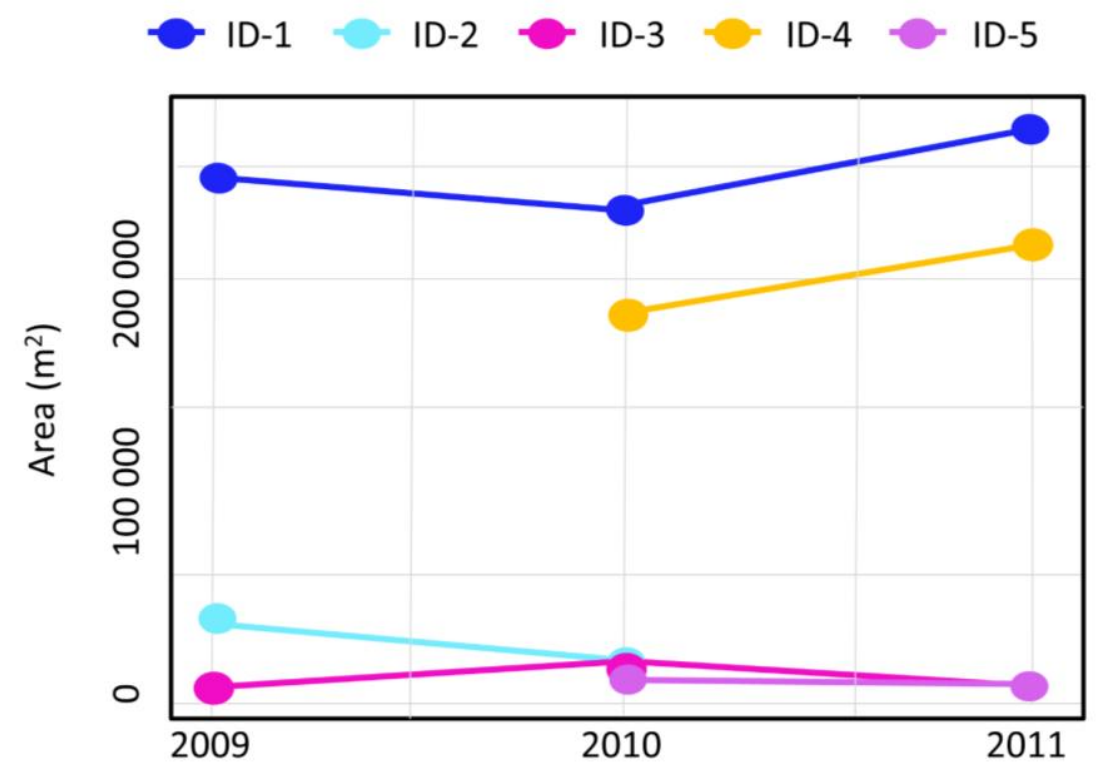

Figure 12: Changes in mapped area for each landslide-dammed lake in 2009, 2010, and 2011. The IDs (1 to 5) are the same as in Figure 11. From Dabiri et al. (2019).

We were able to extract the features of interest from the three Landsat images using a semiautomated OBIA approach. However, we had to adapt the classification thresholds for extracting the different classes from each Landsat image, mainly because the images were taken at different times and under different illumination conditions. The landslide-dammed lakes and their triggering landslides were successfully detected and extracted to a large extent; however, further work should be done to improve the exact delineation of triggering landslides to be able to draw further conclusions on their characteristics and their impact on the channel system. The approach can be useful to monitor the evolution of landslidedammed lakes and triggering landslides at regional scale after typhoon and heavy rainstorm events within an efficient time range.

\subsection{Detection of landslide-dammed lakes on time series of satellite images}

The detection of landslide-dammed lakes using optical satellite imagery was tested at a regional scale for a study case in New Zealand. We focused on the $M_{w} 7.8$ Kaikōura earthquake event, which took place on November 14th, 2016 (Dellow et al., 2017). The earthquake involved the rupture of several active faults that triggered approximately 30,000 co-seismic landslides in North Canterbury and Marlborough, extending over an area of $10,000 \mathrm{~km}^{2}$. The landslides blocked river courses and created approximately 200 landslide dams (Figure 12). The aim of the study was to automatically map the landslide-dammed lakes caused by the earthquake and to monitor their evolution at different points in time, using time series of Sentinel-2 imagery and a pixel-based change detection approach within Google Earth Engine (GEE). The results of the study have been submitted as a journal article to the "Natural Hazards" journal (Abad et al., in review). The main findings are presented in the following subsections. 


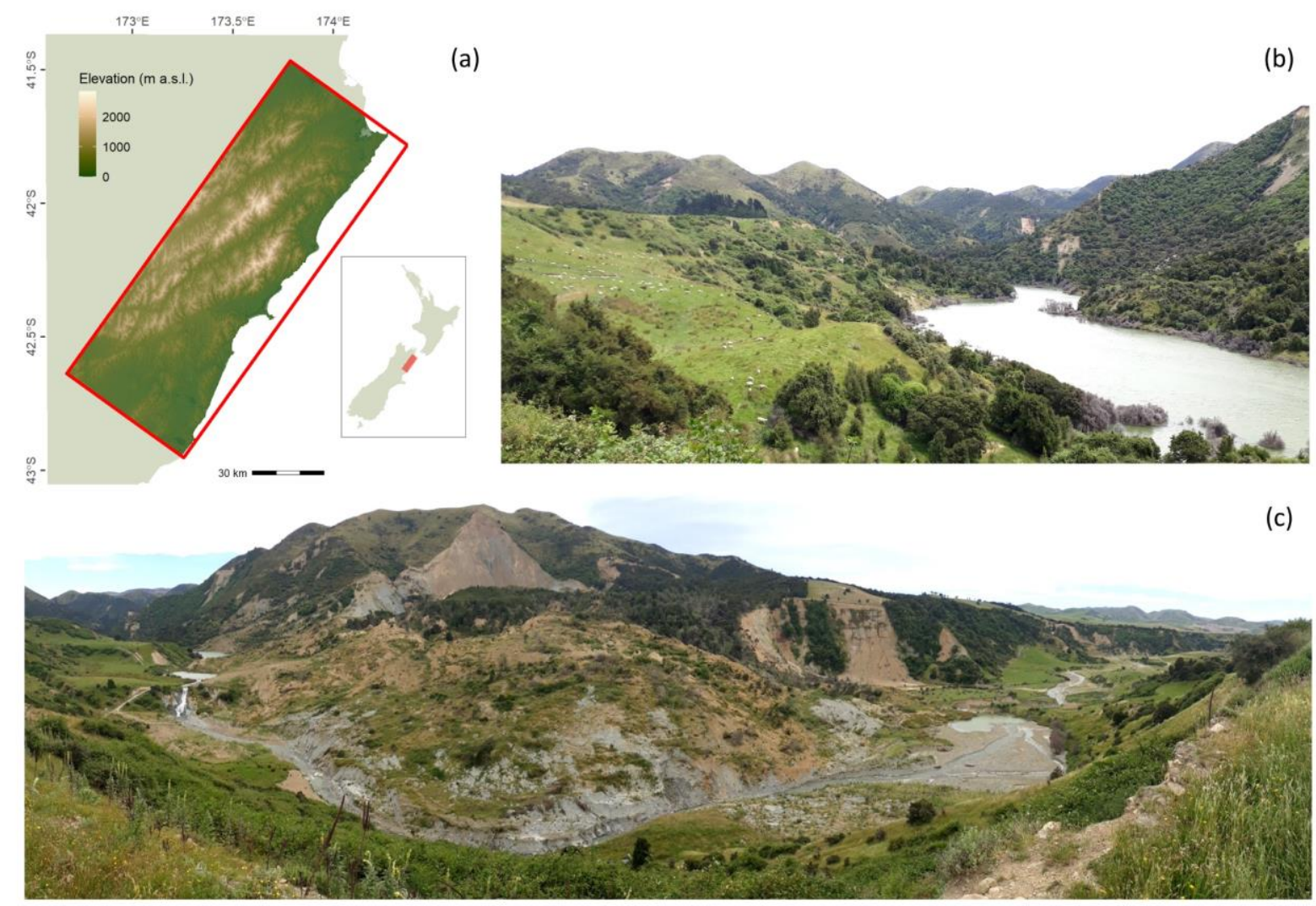

Figure 13: (a) Study area in New Zealand. (b) Example of a landslide-dammed lake and (c) its landslide dam in the Hurunui district, Canterbury (photographs (c) Anne-Laure Argentin 2019; date taken: 03-01-2019). The Leader River was dammed by $\sim 6$ million $\mathrm{m}^{3}$ of material, which impounded a $1.1 \mathrm{~km}$ long lake. Modified after Abad et al. (in review).

\subsubsection{Landslide-dammed lake mapping and monitoring approach}

Cloud computing platforms like the GEE (Gorelick et al., 2017) have transformed the handling and processing of big Earth observation (EO) data. Remote sensing workflows can directly benefit from 1) big EO data archives, available through the Earth Engine Data Catalog, and 2) high-speed and high-performance geospatial analyses by accessing the several pixel-based algorithms available through the GEE API. For this study, we explored the capabilities of the GEE API for the automatic mapping of landslide-dammed lakes at a regional scale by combining dynamic thresholding, change detection, and connected component analyses which allowed a time series monitoring of the impounded lakes area. The approach is schematized in Figure 14, and its strengths and limitations are further explained in the following subsections. 


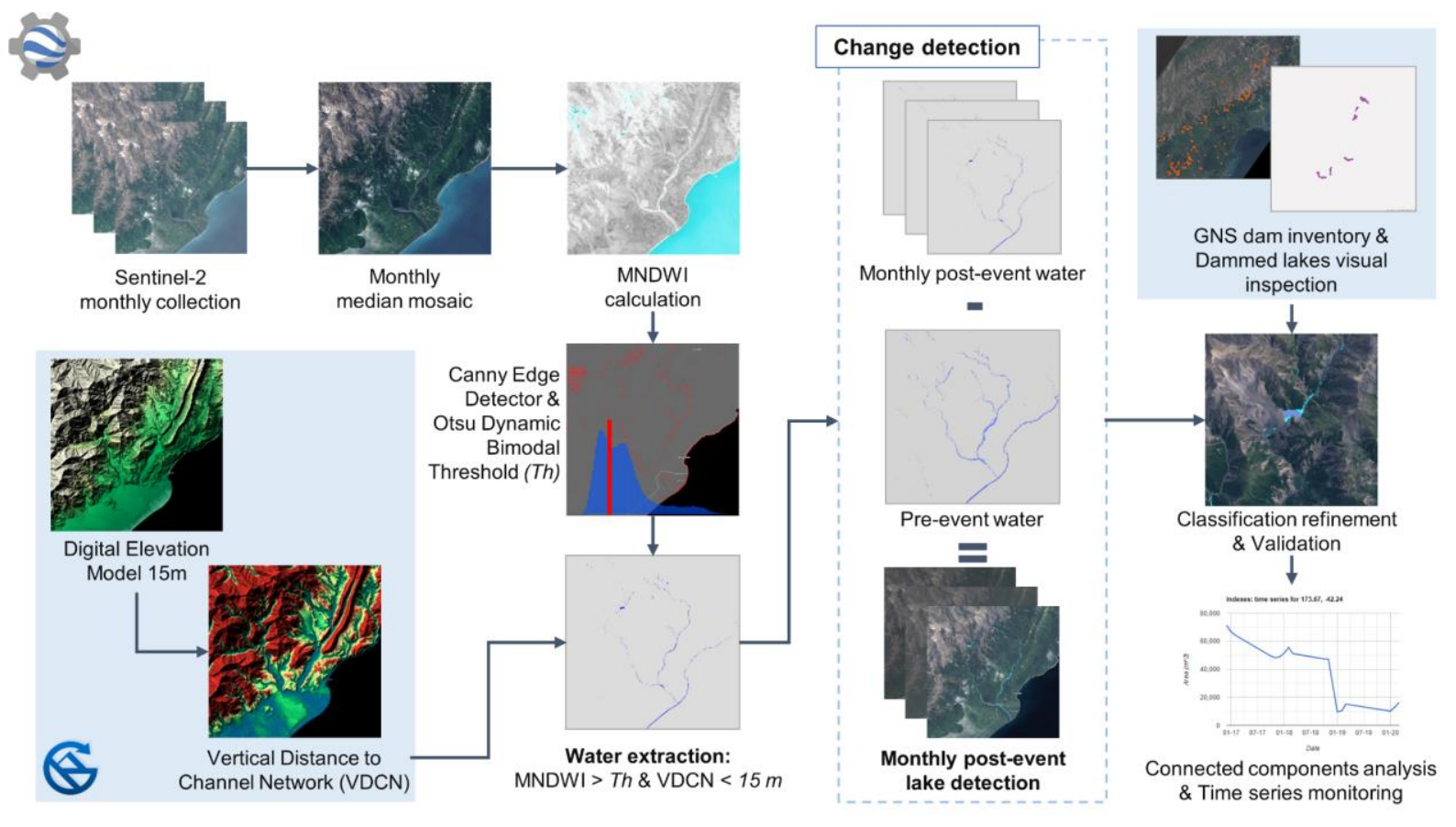

Figure 14: Landslide-dammed lake mapping and monitoring workflow based on the Google Earth Engine. Modified after Abad et al. (in review).

\subsubsection{Water bodies detection through dynamic thresholding}

We created monthly mosaics of Sentinel-2 Top-Of-the-Atmosphere (TOA) imagery with a low cloud coverage (below 30\%) between December 2015 and March 2021. Due to the large area of analysis, obtaining cloud-free monthly mosaics for the entire area was challenging, and hence a visual inspection had to be performed to guarantee the quality of the mosaics. Additional challenges with snow cover, clouds, and topographic shadows made us focus our analysis mostly on summer months, analyzing 22 different timestamps, out of which three corresponded to pre-event dates (December 2015, February and April 2016). Attempts to apply topographic corrections to the Sentinel-2 TOA imagery did not lead to improvements in the quality of the mosaics. Using Surface Reflectance (SR) imagery might lead to better results; however, this extra processing is only available for Sentinel-2 scenes from 2017.

We applied a water detection algorithm written for the GEE by Donchyts et al. (2016). The algorithm consists of a histogram-based Otsu thresholding method based on the Canny edge filter of a spectral water index. Using a Canny edge filter, the differences between the water index values for those areas in the mosaic where water pixels border non-water pixels are better discriminated, ideally in a bimodal distribution, which allows the automatic setting of a threshold value. In practice, this allows for the automatic extraction of water bodies using optical imagery, without the need to manually set threshold values for each timestamp analyzed. Although the approach gave reasonable results for our purposes, mixed pixels did not always result in a clear bimodal distribution, which resulted in false positive detections. Several spectral water indices were tested to evaluate the performance of the algorithm, including the NDWI, the Automated Water Extraction Index (AWEI), the NDVI, and the 
Modified Normalized Difference Water Index (MNDWI). Finally, the MNDWI index (Xu, 2006) was selected as the one with the best results.

A further source of water pixels misclassifications were topographical shadows. A way to bypass this issue was to use DEM-derived information. On the assumption that dammed lakes will only reach a maximum vertical height measured from the riverbed, we applied a threshold of $15 \mathrm{~m}$ to the vertical distance to the channel network (VDCN) derived from a local DEM (15 $m$ horizontal resolution). Using the VDCN as ancillary data greatly reduced the number of false positives outside valley floors, on areas with snow cover or farm dams, which are common in New Zealand's pastoral landscapes. Ultimately, we obtained water masks for each timestamp analyzed for our study area.

\subsubsection{Lake extraction based on pre-and post-event water masks change detection}

Based on the premise that permanent water bodies unaffected by river-damming landslides remained unchanged, we extracted the newly formed landslide-dammed lakes based on the change detection between the pre-event water mask, and each of the post-event monthly water masks. Although this was an effective approach for large landslide-dammed lakes where changes were evident, smaller and medium size lakes, especially those located within steep incised and rugged terrain, were not always detected.

Further, seasonal variations in the water bodies resulted in several false positive results. We worked with three pre-event mosaics, corresponding to December 2015, February 2016 and April 2016. However, the difference in water level between pre- and post-event pairs remained an issue.

Attempts to bypass this included working with mosaics created from Landsat imagery, however, the difference in resolution resulted in unrealistic results. A partial solution we employed to remove water bodies present before the earthquake was to mask out permanent water pixels from the Joint Research Center (JRC) Monthly Water History dataset based on Landsat imagery (Pekel et al., 2016). Lastly, by analyzing the temporal trend of the potential dammed lakes mapped on the post-event water masks, we removed those pixels where water was detected only on 1 of the 19 mosaics, as they were considered to potentially be a cloud-shadow or another type of false positive error.

\subsubsection{Connected component analysis for landslide-dammed lake classification refinement, area calculation and time series monitoring}

The last stage of false positive removal was done through a connected component analysis of the detected landslide-dammed lake pixels. Neighboring water pixels are clustered together, what would imitate an object-based detection approach, allowing to compute the area of the clusters. This enabled the removal of isolated pixels on riverbeds, and the exclusion of water bodies with an area smaller than $300 \mathrm{~m}^{2}$, which is the minimum area that is correctly detected according to the literature (e.g., Freitas et al. 2019), given the limitations of the Sentinel-2 spatial resolution. Calculating the landslide-dammed lakes area also allowed for a time series monitoring of its evolution, based on the 19 post-event landslide-dammed lake mosaics. We 
showcased the time series monitoring with ten landslide-dammed lakes, based on their visibility on Sentinel-2, their size, persistence, and changes in their spatial extent. The findings based on time series monitoring are further summarized in Section Fehler! Verweisquelle konnte nicht gefunden werden..

The validation of the detected landslide-dammed lakes mosaics was based on the selection of two subsets within the study area for three different timestamps, based on the distribution of landslide dams and considering environmental characteristics. The automatically detected landslide-dammed lakes were compared to those lakes that were visible and manually delineated on the Sentinel- 2 mosaics. We further validated the approach by determining the number of landslide-dammed lakes found in the proximity of landslide dams known locations for the whole study area, based on a GNS Science dam inventory (Massey et al., 2018).

Despite the pre- and post-processing efforts previously described, the approach still presented a large number of misclassifications throughout the study area. For this reason, reporting our results on an aggregated regional scale (i.e., number of lakes detected or aggregated lake surface area) was not possible. Nevertheless, the true positive detection of landslide-dammed lakes was satisfactory, reaching similar levels as using object-based image analysis (OBIA) approaches (Hölbling et al., 2020). Our approach represented a fast way of detecting landslide-dammed lake candidates and their locations on a regional scale. These locations can be used to establish a targeted field survey plan, complementing the initial efforts for emergency response after a hazard event that affects large areas.

\subsubsection{Landslide-dammed lake categorization based on spatio-temporal patterns}

Monitoring the evolution of landslide-dammed lakes located on relatively flat terrain was possible at different time periods, which could be potentially expanded to a finer temporal resolution as frequent as every 5 days for Sentinel-2 imagery, provided the areas of interest remain cloud-free. A general overview of the landslide dams' potential hazards can be obtained with the proposed approach while saving resources.

Based on the observed spatio-temporal patterns and changes of the landslide-dammed lakes during the time series monitoring analysis (Figure 15), we were able to suggest the categorization of landslide-dammed lakes in four types:

1) constant, the lake size remains constant over time, which may indicate dam stability.

2) increasing, the lake size increases over time, which might be associated with subsequent secondary slope failures and the related increase in landslide dam height due to the deposition of additional material driving the emergence and expansion of lakes.

3) decreasing, the lake size decreases over time, possibly due to sediment infilling, overtopping, dam erosion or dam breaching,

4) variant, the lake size varies over time without showing a significant increasing or decreasing trend, both revealing periodic variations, potentially influenced by wet and dry seasons, and aperiodic variations. 
The fourth proposed type still needs further investigation regarding the lake variations, definite conclusions can only be drawn when the changes are monitored throughout the whole year, including winter months, and when they are analyzed in relation to other data such as rainfall, water discharge, and lithology.

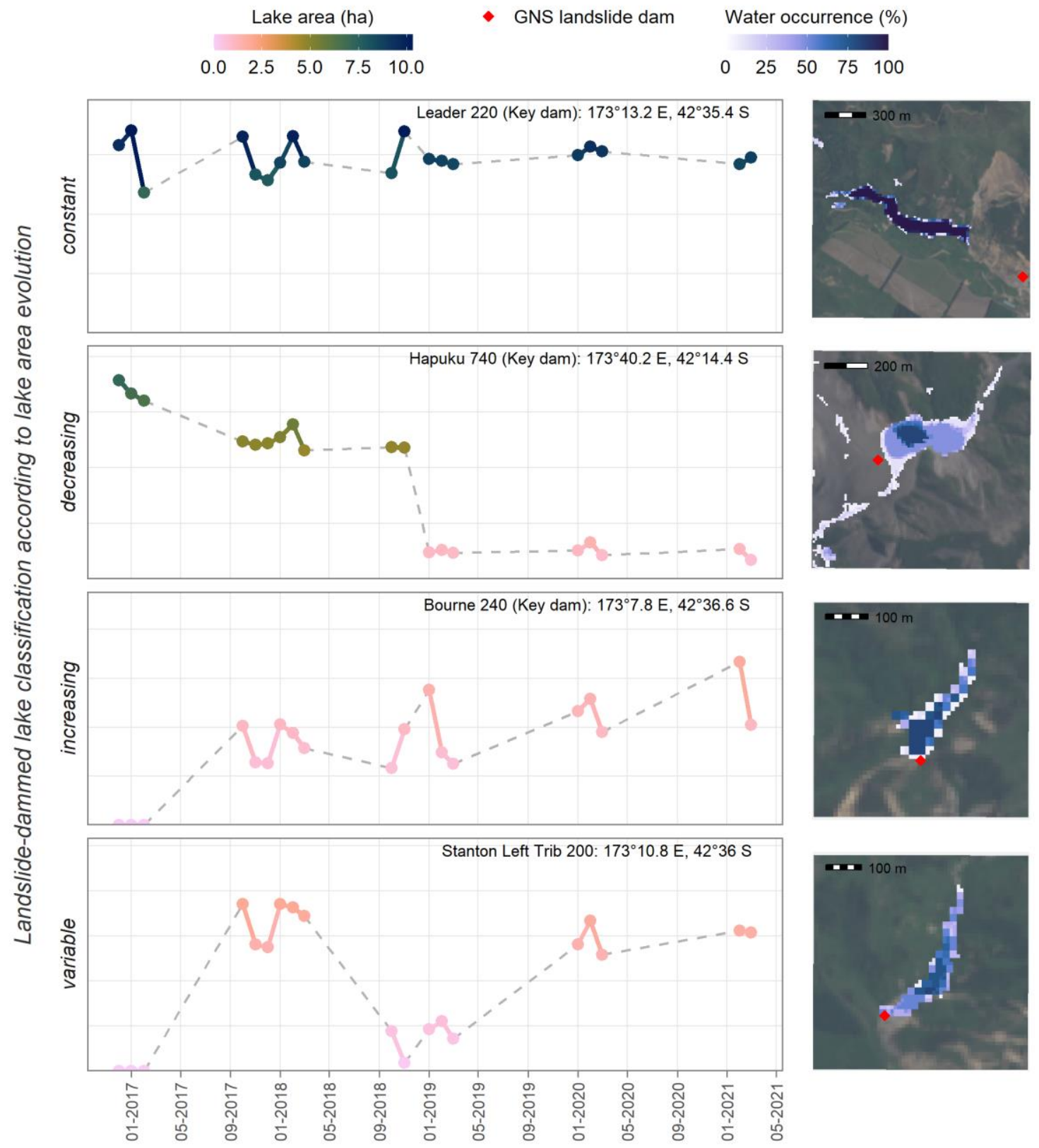

Figure 15: Landslide-dammed lake classification according to the spatio-temporal lake area evolution patterns. From Abad et al. (in review).

Attempts to categorize landslide-dammed lakes are scarce in the literature (Adams, 1981; Cui et al., 2009) and do not incorporate further information about the lakes spatio-temporal evolution. Hence, we believe our categorization scheme can greatly complement landslide damming studies and disaster mitigation. 
The temporal monitoring of hazards is also useful for disaster prevention. Landslide-dammed lakes constitute latent hazards, especially in areas prone to multiple hazards like New Zealand. Temporal and spatial monitoring of dammed lakes contributes to the analysis of potential cascading hazards and their interactions. Our approach can complement current monitoring practices while reducing the time and effort needed for field surveys or manual mapping by automatically monitoring the variations inherent in the lakes. While the availability of EO data does not yet allow real-time monitoring, the approach can be applied to monitor specific lakes that present a potentially high threat to downstream areas. Knowledge about the temporal evolution - and particularly about unexpected changes - in the lake area will enable disaster management teams to take further action.

\subsection{Detection of landslide dams and landslide-dammed lakes on DEMs}

We tested two approaches to identify the local influence of landslides on river courses by analysing only the shape of the landscape. In particular, we looked at the geometry of the river course. This can help to generate data about past landslide-river interactions that are not reported in historical records and cannot be tracked on satellite imagery. Likely, the number of such unwitnessed events is large and capturing their characteristics can add to more complete and versatile inventories.

Flint's Law (Flint, 1974) provides a simple theory to predict the differences in river course geometry that should result from local blocking or sediment input. In the case of a graded stream, channel slope and drainage area (as a proxy for run-off) follow a typical relation. Breaks in this relation hint at a disturbance, for example through a landslide. However, other disturbances, for example with a tectonic or climatic origin, could lead to similar signatures in landscape geometry. Thus, we aimed to assess whether landscape geometry allows the distinction between different influences.

\subsubsection{Theoretical view of a dammed valley landform}

Figure 16 shows idealized geometries of a landslide dam. Two variables strongly affected by a landslide dam are the slope and the valley cross-sectional profile. In the case of a dam with water or sediments accumulated upstream (Fig. 16b, 16d), the channel slope shows a positive anomaly on the downstream part of the dam and a negative on the upstream part. The slope is null on the lake surface, and only slightly positive on the deposited fluvial sediments. The valley cross-section has a wide and flat bottom on the dam, lake and lake sediment locations. For a broken dam fully incised (Fig. 16c, 16e), there are no changes in slope at a small scale anymore. At a larger scale, the valley bottom might remain perturbed by the eroded sediments from the dam. If there has been sedimentation in the lake (Fig. 16e), the slope anomaly migrated upstream in the lake sediments. Incision also coins the valley cross-section. In reality, surface (e.g., glacial erosion) and tectonic processes may have obscured the topographic signal. The river might have already incised through most of the landslide sediments, leaving no abrupt change of slope downstream of the landslide. The only visible pointer of a former dam is the river incision into the landslide sediments (Fig. 16c, 16e). To detect this, a calculation is done for the smallest window possible $(3 \times 3$ pixels). The crosssection is computed using a Python code. Several features and processes can interfere with 
our detection algorithm. To list a few, natural and anthropological dams, lake-like features give similar landforms, and tectonics (faults, differential uplift) and lithology influence the topography similarly.

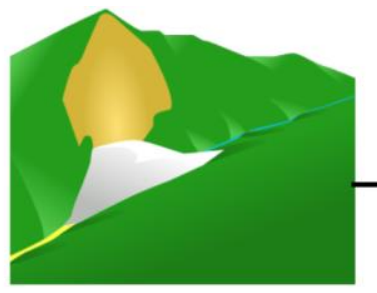

(a) Young dam just formed

Legend:

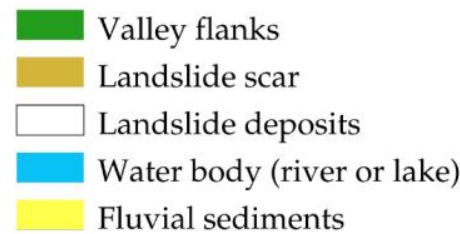

Fluvial sediments

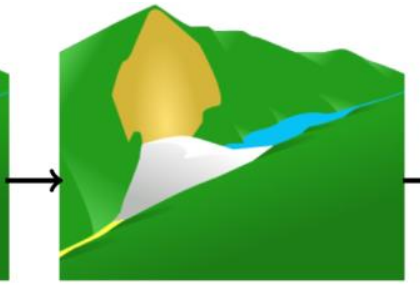

(b) Dam with lake

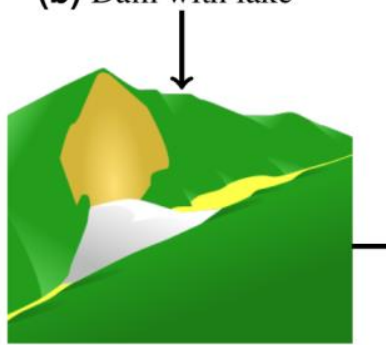

(d) Dam with sediments accumulated upstream

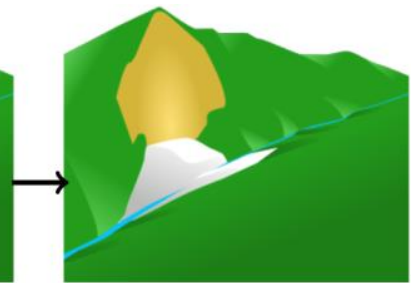

(c) Broken dam

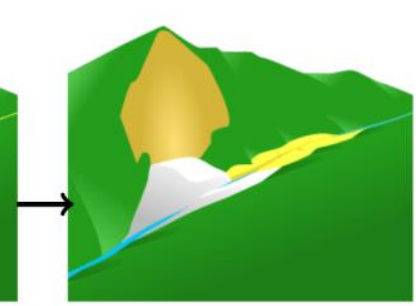

(e) Eroded dam with fluvial sediments

Figure 16: States of a landslide dam over time (Argentin et al., 2020). A landslide forms a dam when its deposits block the river flow (1a). This state is very brief, as very soon, water will accumulate behind the dam (1b), leading either to its failure (1c) or to its filling with fluvial sediments (1d). The filled lake is then eroded by the river (1e).

\subsubsection{Approach 1: A normalized cross-section index}

We use a moving window to analyse the cross-sections of each valley segment in the drainage network on a gridded DEM. We compute the closest representation of the land surface in a $3 \times 3$ cell neighbourhood by a second-order polynomial (Wood, 2008). This method is fast and allows us to find the most concave quadratic surface. The valley direction is found by getting rid of the $x y$ term in the quadratic surface equation $a x^{2}+b y^{2}+c x y+d x+e y+f=0$, through rotation. The quadratic surface gives a parabola in the direction of the cross-section (orthogonal to the valley direction): $a^{\prime} x^{2}+b^{\prime} x+c=0$. We use $a^{\prime}$ as the cross-section index $C$.

Just like the slope along a river, the shape of the cross-section can be expected to depend on drainage area, with the typical $V$-shape of fluvial valley cross-sections widening with increasing drainage area. We thus defined a "normalized cross-section index" following the model of the normalized steepness index (Flint, 1974): $k_{\mathrm{cn}}=C A^{\theta_{c}}$ with $C$ the cross-section index, A the upstream drainage area and $\theta_{c}$ a constant.

Unfortunately, the approach was too sensitive to different kinds of irregularities in the channel network, as well as changes in the geological and climatic setting, leading to a too large number of false positive and negatives. We thus did not further pursue this approach, although the theoretical foundation has some merit and should be explored further, for example in the frame of landscape evolution theory. 


\subsubsection{Approach 2: upstream region growing}

In approach 2, we simplified the theory on channel geometry to the utmost point to detect un-incised lakes and sediments. Upstream of a river blockage, the channel on a DEM should be flat or nearly flat. Thus, we ran a region growing algorithm with each flow path cell on a DEM as a starting cell. Beginning at the starting cell, the region is recursively grown upstream, iteratively enlarged by the cell with the largest drainage area of all upstream neighbouring cells. If a slope criterion along the flow length of the entire region is exceeded, the region dedicated to the starting cell has reached its maximum extent. If its area is larger than the minimum expected lake size, it is considered a dammed lake and the principal cell is considered the location of a dam.

The approach worked well on a synthetic landscape designed to obey Flint's Law. Further, it was able to detect all six landslides investigated by Finnegan et al. (2019) in California without any false negatives and an artificially levelled agricultural area as the only false positive (Fig. 17a). We chose this study as a reference, because a Lidar-based DEM with very high quality and resolution was available for free. In any case, the generalization of this approach remained problematic. First, other influences such as glaciation and tectonics can produce flat reaches. Second, extensive, high quality DEMs would be needed to distinguish between the different influences on the river course but are hardly available for relevant study areas. One example is the Pamir region, home to some of the most prominent known river damming events but also shaped by vigorous tectonics and glacial erosion. Based on the SRTM DEM with $90 \mathrm{~m}$ resolution, the algorithm was able to detect 5 out of 6 prominent landslide dams but also produced numerous false positives at tectonics features such as faults and the rim of the Pamir plateau and glacial sedimentation plains (Fig. 17b).
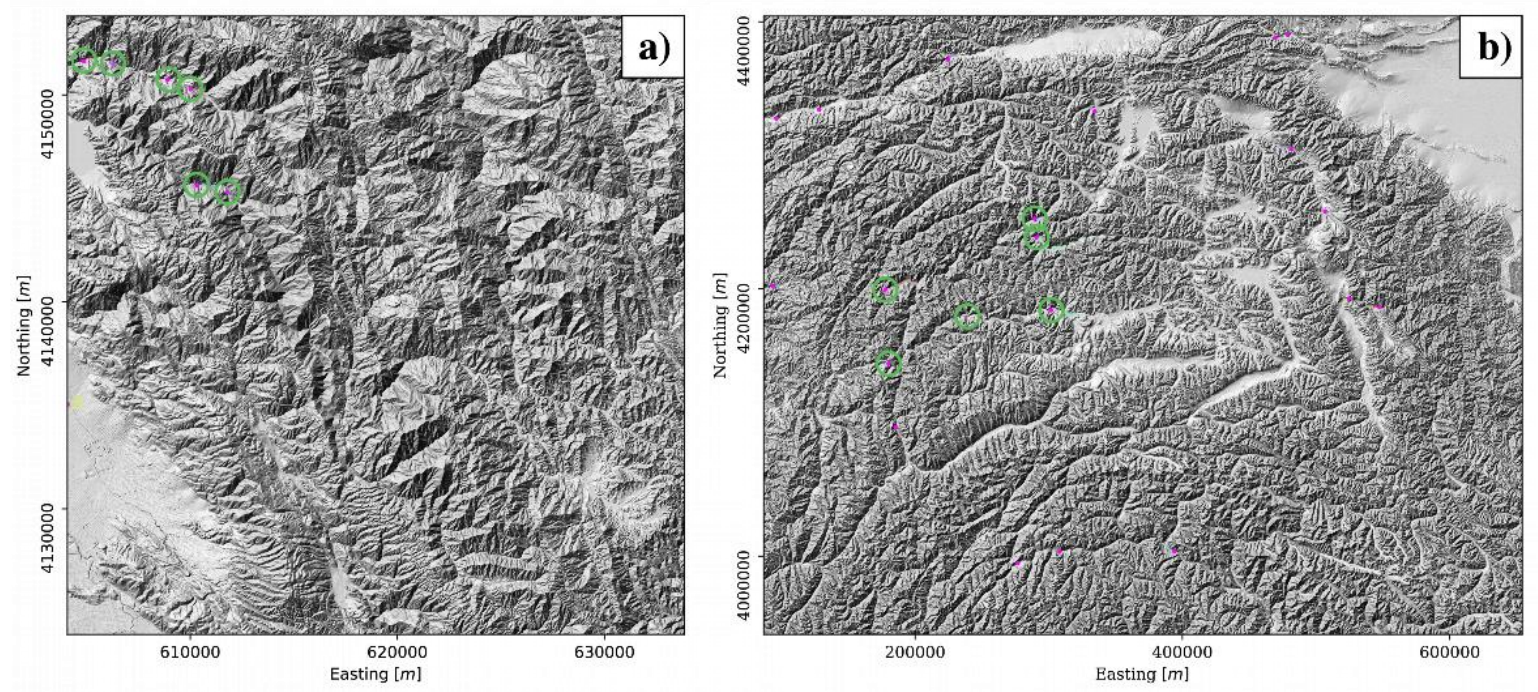

Figure 17: Locations of existing landslide dams identified by a region growing algorithm. a) Franciscan Mélange area in California, b) Pamir Mountain range. Pink dots denote classified dams, green circles mark reported damming.

Due to the issues with other influences obscuring flow path geometry in conjunction with too low DEM quality, we did not further pursue the automated detection of landslide-river interactions solely on DEMs but chose another approach to learn about the distribution of 
landslide-dammed lakes and controlling variables based on digital topography: We numerically simulated the occurrence of landslides and their interaction with rivers on realworld topography.

\subsection{Simulation of landslide-dammed lake occurrence on DEMs}

We simulated landslide-dammed lakes on DEMs to get a comprehensive picture of the reasons why a landslide dam form, how potential landslide-dammed lakes are distributed across a mountain range, and how dam and lake characteristics are related and vary regionally as a function of drainage area, topography and rock type. While landslides and their occurrence have been extensively studied, supported by monitoring techniques ranging from remote sensing to geophysics (e.g., Nichol and Wong, 2005; Hölbling et al., 2012; Stähli et al., 2015), and modelling of landslide distribution (Hergarten, 2012) and susceptibility (Reichenbach et al., 2018), potential damming of rivers by landslides and resulting lakes received less attention Korup (2005). By simulating the development of landslide-dammed lakes, we were able to overcome data scarcity and determine new and complement established relationships between landslides, lakes, topography, and the drainage network.

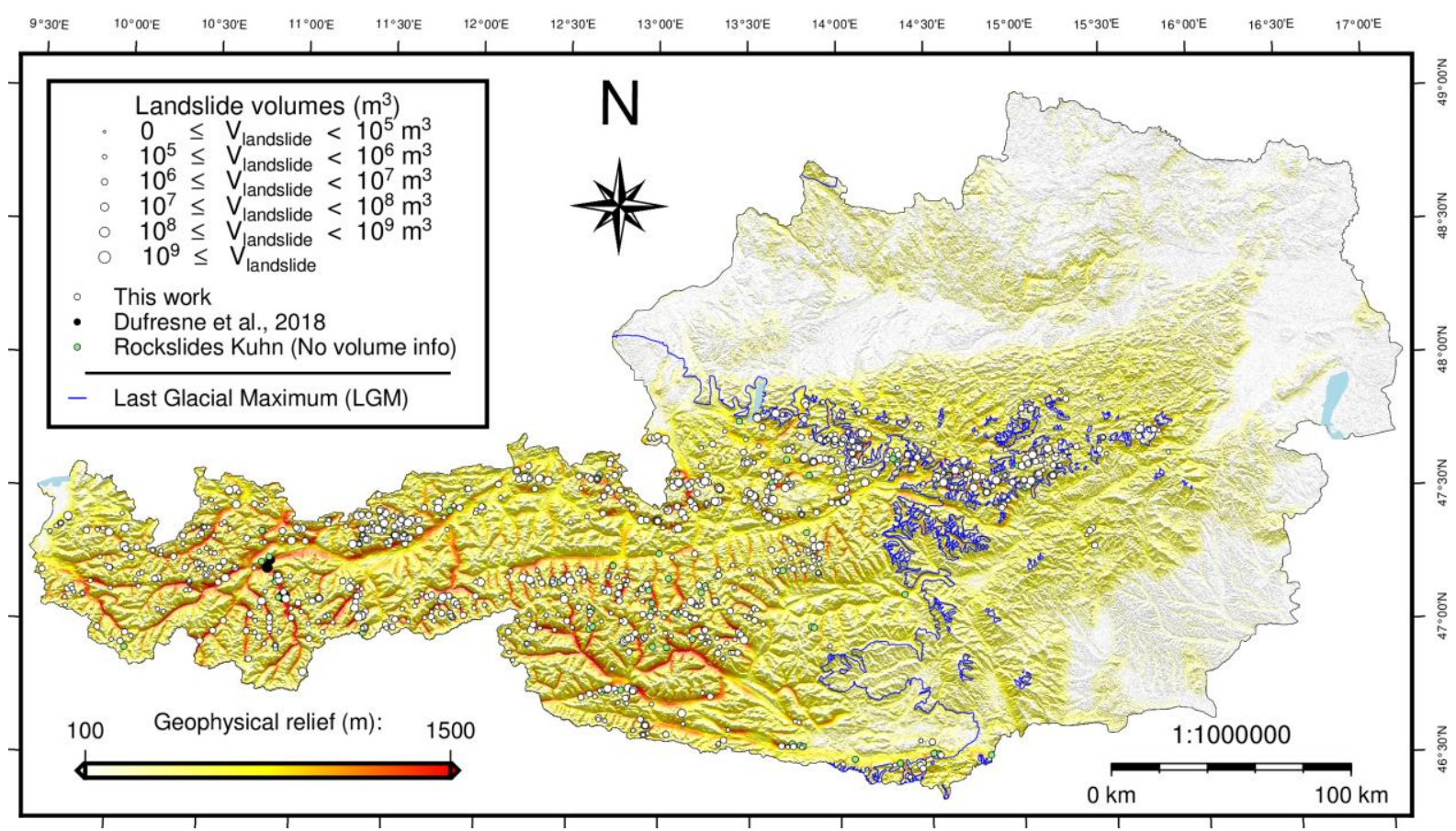

Figure 18: Comparison of the distribution of modelled landslides and reported large mass movements in Austria (Argentin et al., 2020). Last glacial maximum ice extent is depicted by a blue line (Ehlers and Gibbard, 2004). DEM data obtained from OpenData Österreich (starting 2015).

To simulate landslide release areas, resulting dams and dammed lakes, we combined three modelling techniques to a new approach. We determined landslide release areas based on landscape geometry and probability following Hergarten (2012). We then modelled the progression of the landslides and deposition of the landslide dams with a fluid dynamic model (Popinet, 2003). Finally, we filled the retention space upstream of the deposits with a sink fill approach with GRASS GIS. We applied this approach in two studies. 


\subsubsection{Study 1: Potential landslide-dammed lakes in Austria}

In the first study, we investigate the influence of topography and glacial imprint on the potential occurrence of landslide dams and landslide-dammed lakes in Austria. The study was published in Argentin et al. (2020). Further, we quantitatively investigated landslide and lake characteristics. This has not been done before in Austria. In fact, an exhaustive database of large, rapid mass movements in Austria does not exist and existing heterogeneous landslide collections lack crucial information such as release area or volume (Kuhn, 2020). For dammed lakes, no data collection exists to our knowledge.

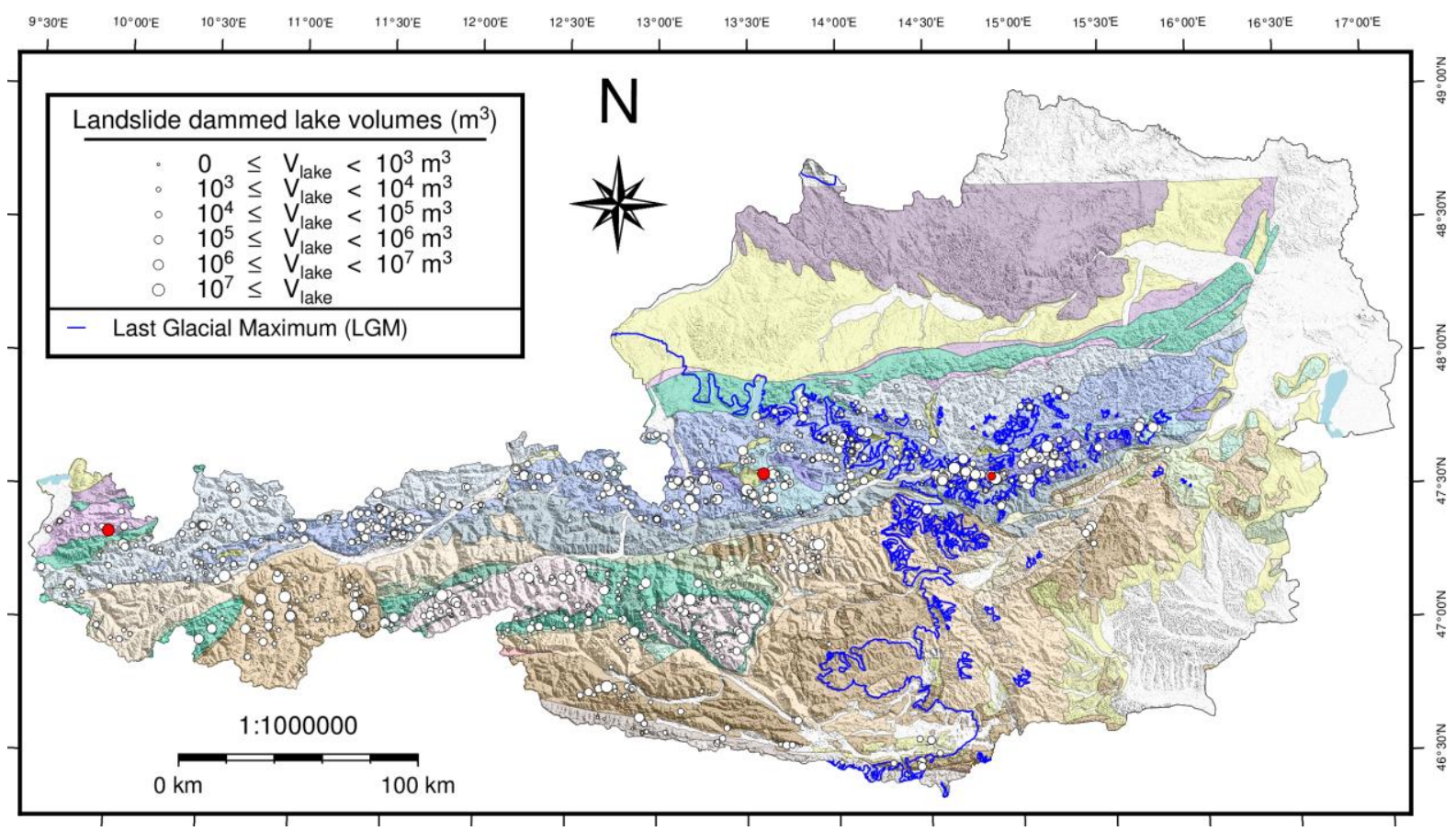

\begin{tabular}{|llll}
\hline Tectonic units: & Alpine Tethys \\
European Continent \\
Helvetic Nappes and Northern \\
Alpine Foreland
\end{tabular}

Figure 19: Spatial distribution of modelled landslide-dammed lakes in Austria Alps (Argentin et al., 2020) plotted on a map of tectonic units modified after Bousquet et al. (2012). Last glacial maximum ice extent is depicted by a blue line (Ehlers and Gibbard, 2004).

\subsubsection{Distribution of modelled landslides and lakes}

We modelled approximately 1000 landslides and lakes in Austria, more than 20 times the amount of large mass movements collected by Kuhn. Landslide distribution predicted by our 
model conforms to observations (Kuhn, 2020). This confirms that slope and relief are reasonable predictors for the occurrence of rapid mass movements (see also e.g. Hergarten, 2012) (Fig. 18). Most efficient damming, i.e., dammed lakes with exceptionally large volumes relative to the deposit volumes, is predicted in several regions across Austria, all characterized by exceptional valley relief. In particular, very large lakes are formed by landslides damming relatively narrow valleys downstream of wider and flatter valley sections (red dots mark examples in Fig. 19). This highlights the role of valley geometry in controlling the efficiency of damming. Further, our results suggest that a change of tectonic units and thus rock strength along a river leading to a narrow section at the damming location and a wider section upstream favours efficient damming and the formation of very large lakes. In the Austrian Alps such settings occur in the Northern Calcareous Alps (e.g., Enns river, Salzach river).

\subsubsection{Controls on lake volumes}

Our results imply that the range of landslide-dammed lake volumes is commonly underestimated in existing databases. Small landslide dams and lakes often remain undiscovered in the field as they may only exist for a short time. While they can hardly be accounted for in field surveys (Dufresne et al., 2018; Korup, 2004; Costa and Schuster, 1988; Fan et al., 2020), they can be simulated leading to a wider range of modelled lake volumes (Fig. 20a) and thus in the widely used Impoundment Index (e.g. Korup, 2004).

Glacial imprint has a strong influence on the occurrence and size of predicted landslides and lakes. The landslides in glacial terrain were 2.8 times more voluminous and dammed 2.5 times bigger lakes, but generally with a reduced damming efficiency. We again attribute these differences to valley shape. The wide valley floors in glaciated areas demand for higher landslide volumes to dam the entire valley. Thus, partial damming is more common. On average, the much higher release volumes in glacial landscapes almost compensate the wide valley floors. This in conjunction with flat and wide valley floors leads to the formation of bigger but shallower lakes.

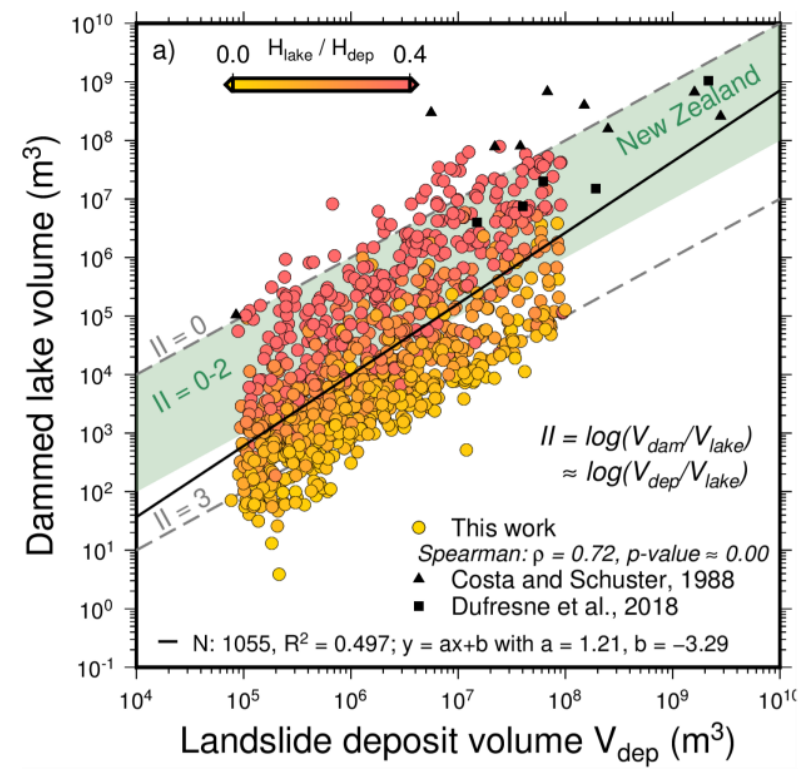

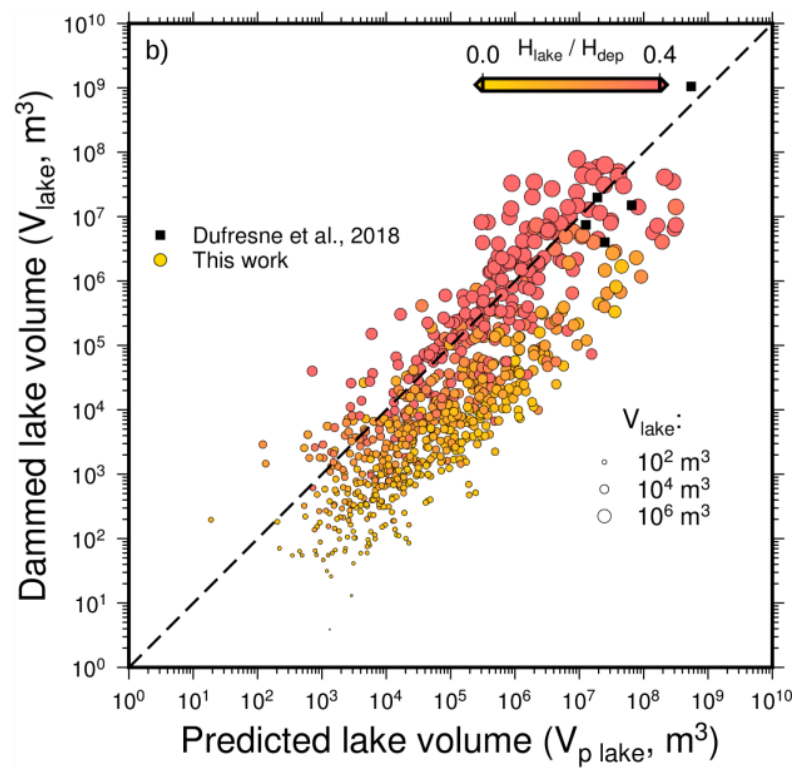


Figure 20: a) Modelled Landslide and lake volumes compared to real world data and reported values of the impoundment Index (Argentin et al., 2020). b) Predicted $\left(V_{p}\right.$ lake $)$ vs. modelled $\left(V_{\text {lake }}\right)$ landslide-dammed lake volume. Circle size represents dammed lake volume. 1:1 relation depicted by dashed line. Colours depict damming efficiency (yellow: low; red: high).

Our results allow to establish a new simple approach to predict landslide-dammed lake volumes from landslide volumes and drainage area (Fig. 20b). The lake volumes are proportional to the volumes of the triggering landslides $\left(V_{\text {landslide }}\right)$ and the drainage area $\left(A_{b}\right)$ of the location of formation, such that

$\mathrm{V}_{\mathrm{plake}} \sim \alpha \cdot \mathrm{V}_{\text {landslide }}{ }^{0.98} \cdot \mathrm{A}_{\mathrm{b}}{ }^{0.92} \times 10^{-6}$

This relation holds for $\alpha=0.003$ with $R^{2}=0.69$ for all modelled lakes in Austria and works particularly well for efficient damming (Fig. 20b, red dots). We hence attribute most of the remaining variability in lake volumes to valley shape. The exponents on $A_{b}$ and $V_{\text {landslide }}$ can be simplified to 1 without losing much accuracy (Fig. 20b, dashed line). This new relation can provide a first estimation of potential dammed lake volume from only two variables. Drainage area can be easily obtained with standard DEM tools. Thus, for locations with given $A_{b}$, different landslide and lake scenarios can be quickly evaluated. 


\subsubsection{Study 2: Global scaling of landslide and dammed lake characteristics}
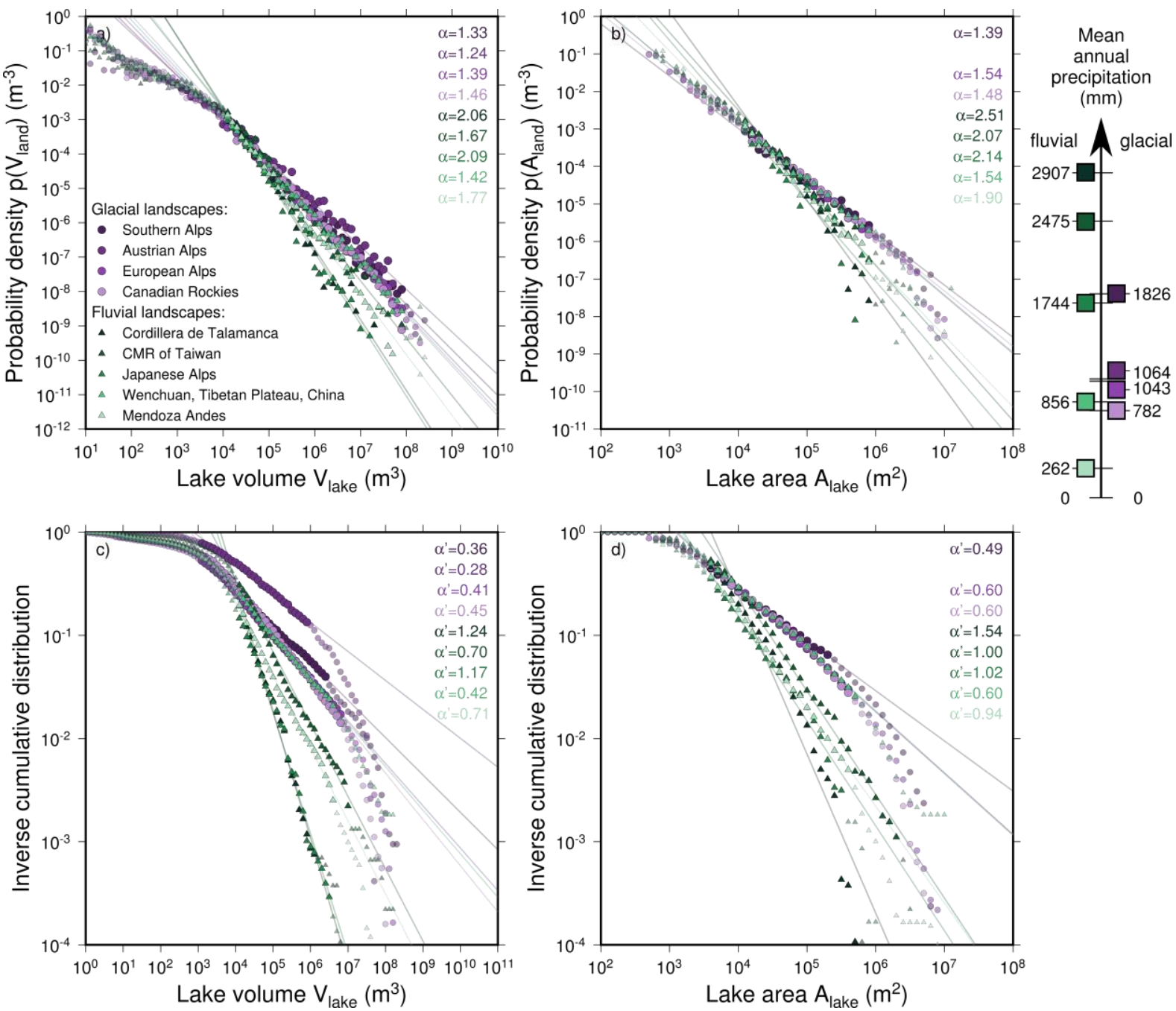

Figure 21: Comparison of the obtained probability densities of landslide-dammed lake volumes (a, b), and of the inverse cumulative probabilities (Argentin et al., in review). The results are binned using logarithm base 10 and bins of 0.1 .

In the second study, we investigate the scaling of landslide-dammed lakes. We modelled almost eight million landslides and more than 50 thousand dammed lakes across eight mountain ranges worldwide with differing tectonic and climatic conditions. The study is currently under review in Earth and Planetary Science Letters (Argentin et al, in review).

It has been shown that the frequency-magnitude distribution of landslides follows a powerlaw (see Section OFehler! Verweisquelle konnte nicht gefunden werden.). We simulated landslides and lake formation in different mountain ranges around the globe to assess if lake sizes show a similar pattern, and it differs between mountain ranges. We used DEMs from the shuttle radar topography mission with a resolution of 1 arc-second ( $30 \mathrm{~m}$ at the equator). Again, we employed our model to circumvent data scarcity. In particular, the number of reported large, dammed lakes is small, even globally, and thus such an analysis is tricky. However, we did use existing data for comparison. 
We found that the scaling of landslide-dammed lakes follows a power-law, similar to that of landslides (Fig. 20). Steep distributions (high exponents) indicate a tendency to small lakes and vice versa. Glacial and fluvial mountain ranges feature different distributions. Further, precipitation is a key control on the landslide distribution but not on the lake distribution in fluvial mountains. In further contrast to landslides, the scaling of landslide-dammed lakes is less sensitive to mountain relief and valley shape. Since landslide-dammed lake volumes depend on landslide volumes but also on drainage area, damming efficiency and valley and dam geometry, the scaling of landslide-dammed lakes does not have to be identical to the scaling of landslides. Our results thus indicate that efficient damming in fluvial mountain ranges makes up for smaller landslides and that they are equally susceptible to the formation of large landslide-dammed lakes as glacial mountain ranges. They may either be more susceptible to dam breaks and catastrophic flooding and efficient dams (damming a large water volume compared to the dam volume) show a higher tendency to fail.

Further, we find that the NZ Southern Alps show a tendency towards larger landslide-dammed lakes than the European Alps, despite similar glacial history. This is consistent with the findings of Korup (2005) and could be caused by tectonics, which also exerts a strong influence on slope and relief. Parts of the NZ Southern Alps exhibit much higher uplift rates than the European Alps (e.g., Herman et al., 2013).

We conclude that tectonics and climate control the potential and formation for landslidedammed lakes. It follows that the parameters of the law to estimate dammed lake volume from drainage area and landslide volume found in study 1 differ between mountain ranges.

The found scaling can help develop a statistical assessment of risk and an estimate of the recurrence time depending on magnitude and mountain range characteristics, in particular for big events, where data is scarce. The consequences of this landslide-dammed lake scaling can also be interpreted in terms of sediment transport and resulting effects on terrain downstream (Cossart, et al. 2008).

\subsection{Other findings}

\subsubsection{The Hintersee landslide-dammed lake}

We conducted a case study on the Hintersee lake in Bavaria, Germany, in the frame of a master thesis. The lake is located $15 \mathrm{~km}$ west of Berchtesgaden. Its surface is around 0.146 $\mathrm{km}^{2}$, its actual volume is $1.148 .000 \mathrm{~m}^{3}$. The lake has been formed after a major landslide event. Mapping and analyses of the composition of the deposited mass allowed to reconstruct the landslide source area. The valley flank is west-facing and inclined between $35^{\circ}$ and $45^{\circ}$. The Dachstein limestone forms compact layers of parallel exposed sediments. The initial thickness of the landslide mass was between 70-100 meter with a reconstructed volume of 12-16 $\mathrm{M} \mathrm{m}^{3}$ (Klappacher \& Knapzyk, 1979).

The master thesis project is currently ongoing. It aims to reconstruct the landslide, the deposition of the dam and the formation of the lake in a detailed study based on the modelling approach described earlier. For this, the landslide deposits and lake sediments are 
removed from the current land surface by extrapolating the valley flanks into the deposits (e.g., Schrott et al., 2003). Extrapolation is done along one longitudinal valley profile and 20 valley cross-sections (Figure 22) and further constrained by taking a neighbouring valley of similar size as a reference template. In this way, we arrive at several scenarios, which allow us to study the progression of the landslide and estimate a range of possible lake volumes.

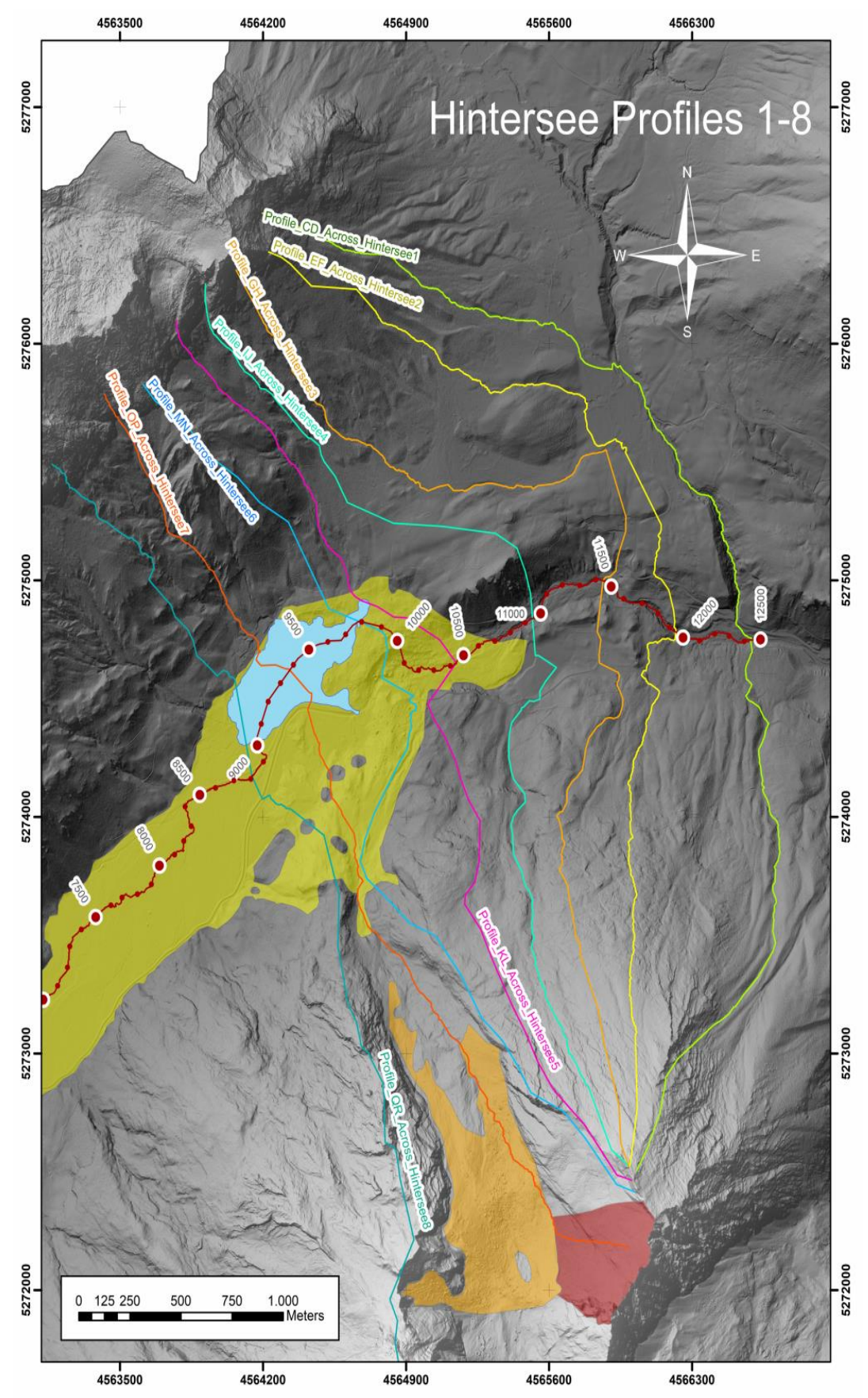

Figure 22: Map of the source area of the landslide (red), upper deposit area (orange), landslide dam and lake sediment (yellow) and current extent of the landslide-dammed Hintersee lake (blue). First 8 cross-sectional profiles of the 21 made in the area to reconstruct the topography prior to landsliding. 


\subsubsection{Assessment of landslide-induced geomorphological changes using Sentinel-1 and Sentinel-2 data}

We developed an OBIA approach to map geomorphological features in a study area in Iceland, where a recent landslide, the Hítardalur landslide dammed a river and led to the creation of a dammed lake and changes in the watercourse using optical and synthetic aperture radar (SAR) data from Sentinel-2 and Sentinel-1, respectively (Dabiri et al., 2020). The Hítardalur landslide occurred on the 7th of July 2018, in western Iceland. It was estimated that approximately 7 million $\mathrm{m}^{3}$ of material were released and a total of $10-20$ million $\mathrm{m}^{3}$ of material were displaced, with a runout length of about $1.6 \mathrm{~km}$ (Helgason et al., 2019). The Hítardalur landslide is considered as one of the largest landslides in Iceland in historical time. For this analysis, we used pre-event Sentinel-1 and Sentinel-2 images (Figure 23).

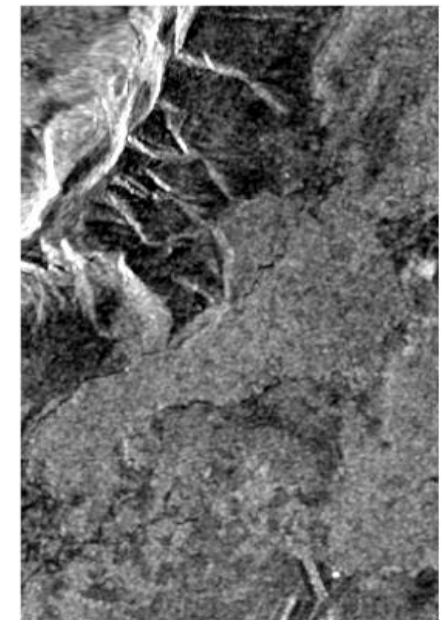

(a)

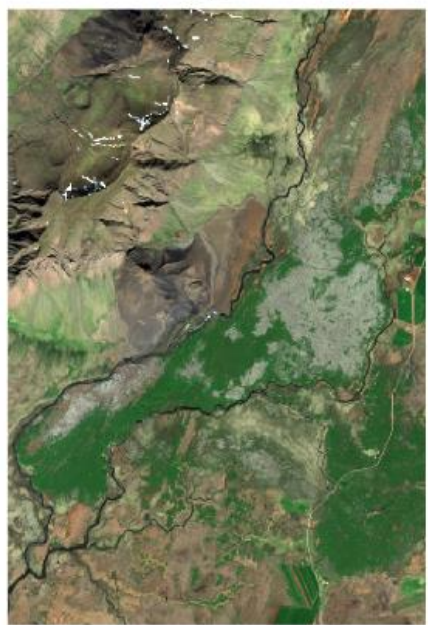

(d)

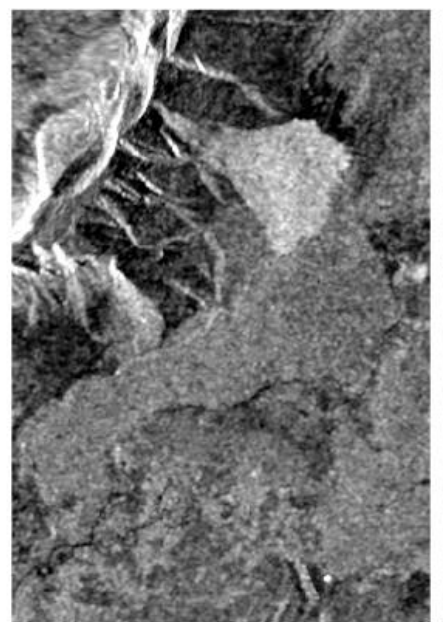

(b)

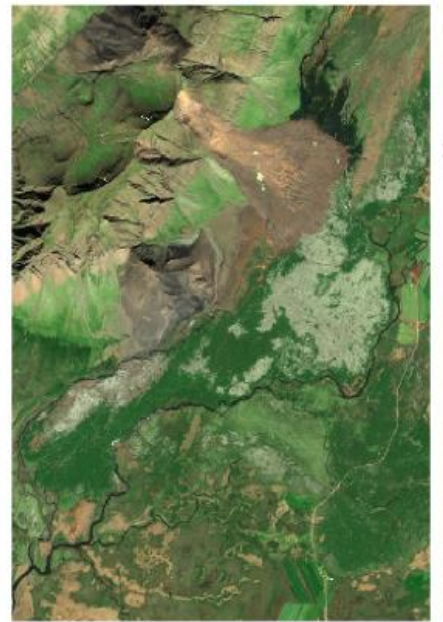

(e)

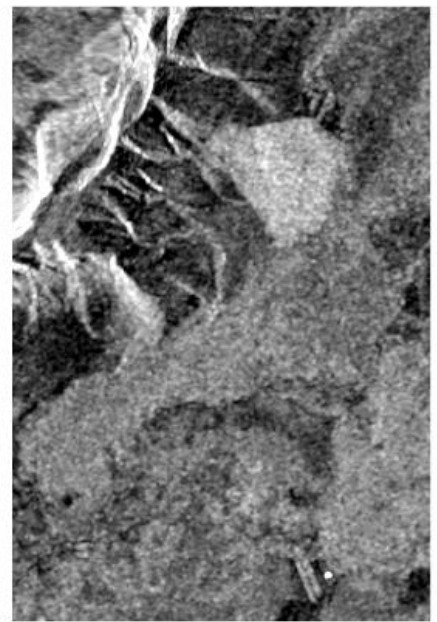

(c)

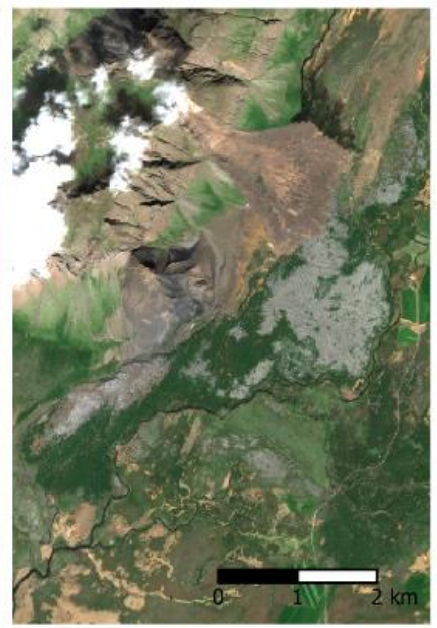

(f)

Figure 23: Sentinel-1 and Sentinel-2 datasets used for geomorphological features mapping. The upper row shows the intensity layer for Sentinel-1 VV polarization for the following image acquisition dates: (a) 2018/07/05; (b) 2018/07/17; and (c) 2019/08/05. The lower row shows the true color composites of the Sentinel-2 images with the following acquisition dates: (d) 2018/06/20; (e) 2018/07/17; and (f) 2019/08/01. From Dabiri et al. (2020). 
The mapping of geomorphological features focused on the Hitardalur landslide, the landslidedammed lake, and the riverbed with flowing water. Additionally, we differentiated between landslide source and deposition area and identified changes in the watercourse based on the pre-and post-event images. We used an OBIA approach and created a knowledge-based classification ruleset in eCognition (Trimble) software, integrating Sentinel-1 and Sentinel-2 datasets. We used spectral indices derived from the Sentinel-2 data, including a brightness layer (average of the three visible spectral bands blue (B2), green (B3), red (B4)) and the NDVI. For the detection of riverbeds we calculated an edge extraction layer based on the Sentinel2 NIR (B8) spectral band using the Lee Sigma (Lee, 1983) algorithm. We also used the intensity information from the pre- and the post-event Sentinel-1 VV, and VH polarization intensity images to create subtraction layers for 2018 and 2019. The Sentinel-1 intensity subtraction layers and the edge extraction layers derived from band B8 used for the object-based classification for 2018 and 2019 are shown in Figure 24.

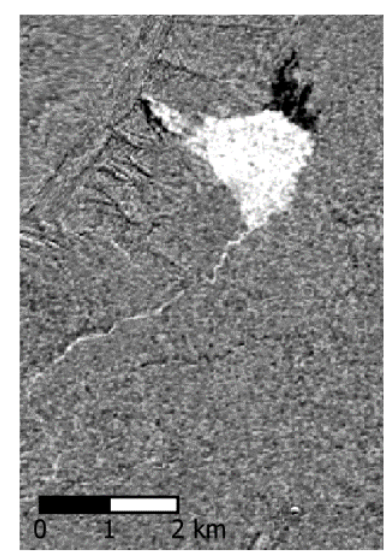

(a)

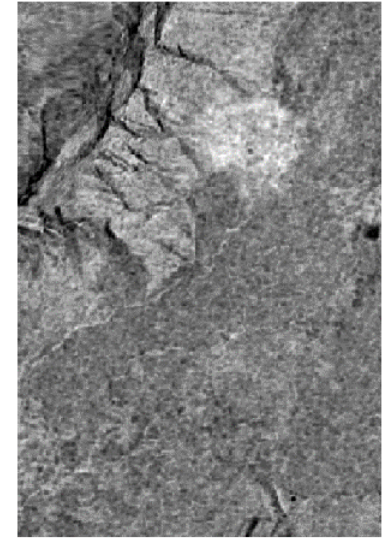

(b)

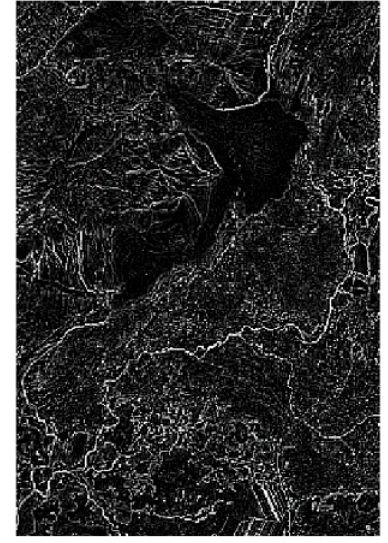

(c)

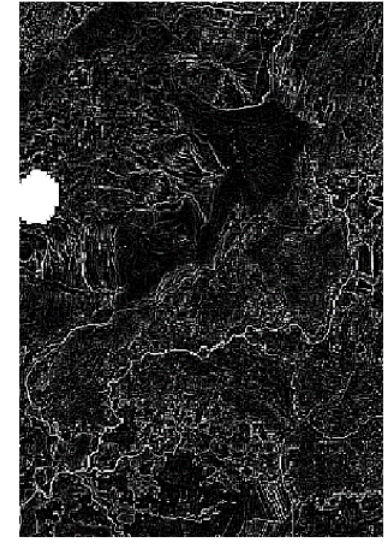

(d)

Figure 24: Examples of the layers extracted from the Sentinel-1 and Sentinel-2 datasets. (a) and (b) show the subtraction layers using pre- and post-event Sentinel-1 VV polarization intensity images for 2018 and 2019, respectively. The Hítardalur landslide (white) and the landslide-dammed lake (black) are distinguishable. (c) and (d) show the edge extraction layers derived from the post-event Sentinel-2 images (NIR band (B8)) for 2018 and 2019, respectively. From Dabiri et al. (2020).

The results of the geomorphological features mapping are shown in Figure 25. The pre-event result shows the original Hítará riverbed with water (Figure 25a). The post-event results (Figure 25b for 2018 and Figure 25c for 2019) show the landslide, the landslide-induced changes in the watercourse, and the landslide-dammed lake. The reference map from NLSI (National Land Survey of Iceland, 2020), which was used for comparison, is shown in Figure $25 d$. 


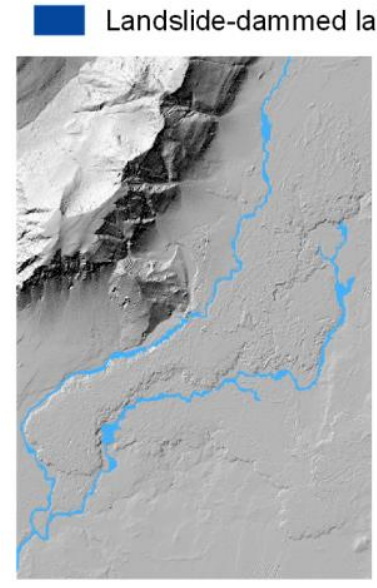

(a)

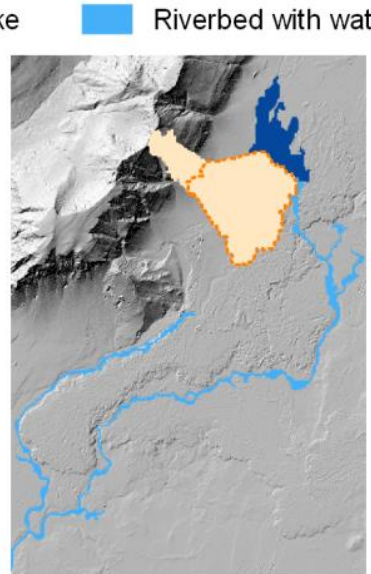

(b)

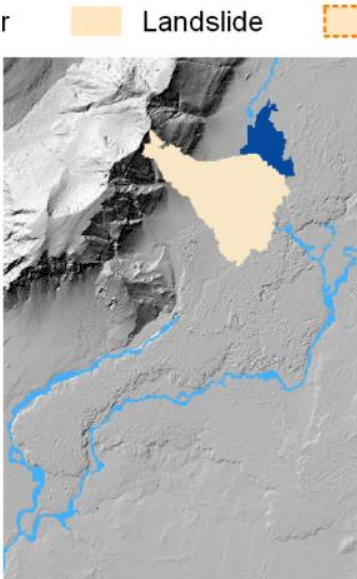

(c)

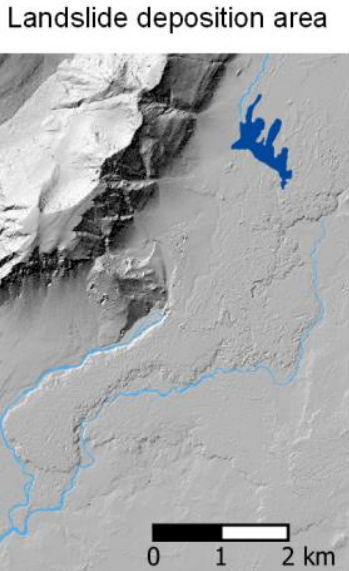

(d)

Figure 25: The results of object-based geomorphological features mapping using Sentinel-1 and Sentinel-2 datasets. (a) shows the riverbed with water before the Hítardalur landslide happened using the pre-event Sentinel-2 image only; (b) shows the landslide, the landslide-dammed lake, and the riverbeds with water after the landslide event in 2018; (c) shows the landslide, the landslide-dammed lake, and the riverbeds with water in 2019; (d) shows the reference map from the National Land Survey of Iceland (IS 50V 24/12 2019 Vatnafar Flakar; available online: https://www.Imi.is). The hillshade derived from the ArcticDEM was used as a background layer. From Dabiri et al. (2020).

As shown in Figure 25, the water flowing out from the dammed lake found a new way towards the south, leading to more water flowing in this riverbed than before the landslide happened. The landslide area was estimated to be approximately 2,000 ha for 2018 and 2019. Slight differences in the landslide areas likely results from variations in the image segmentation. We estimated the lake area of 58 ha for 2018 and 47.1 ha for 2019. The reference value for the lake area reported by Helgason et al. (2019) is approximately 47 ha. This reveals an overestimation of the OBIA result for the year 2018. This can be associated with a high moisture content near the lakeshore and shallow water areas with high sediment load, which introduce uncertainty in the segmentation and classification (Hölbling et al., 2020). The lower value for 2019 can be associated with the warm summer in 2019 that caused the discharge for some rivers to be low for a few weeks (Iceland Met Office (IMO), 2020). The maximum width of the landslide deposition is approximately $1.5 \mathrm{~km}$, and the overall runout length of the landslide is approximately $2.3 \mathrm{~km}$. These results are in line with the numbers reported by Helgason et al. (2019).

Although many applications use EO datasets for landslide mapping, studies for integrating intensity information derived from Sentinel-1 SAR data with spectral information from Sentinel-2 optical data are still rare. This study shows that the combined use of Sentinel-1 radar and Sentinel-2 optical data offers remarkable opportunities for assessing landslides and their interaction with the river channel system. Moreover, the high spatial and temporal resolution, free availability, and the integrated and effective use of Sentinel-1 and Sentinel-2 datasets can contribute enormously to analyzing such events and their consequences (Dabiri et al., 2020). 


\subsubsection{Additional case studies}

The concepts and methods developed in RiCoLa could partly be transferred and applied to other studies that addressed related thematic areas and research questions. By that, we could demonstrate the value of the research done in RiCoLa in a broader sense. This includes, for example, a study on the comparison of pixel-based and object-based methods for landslide susceptibility mapping in Salzburg, Austria (Gudiyangada Nachappa et al., 2020). The results showed that the object-based approach led to a higher accuracy than the pixel-based approach. Another landslide susceptibility study used two methods for landslide susceptibility assessment, i.e., Landslide Statistical Index (LSI) and Analytical Hierarchy Process (AHP), for a study in Freetown, Sierra Leone (Restrepo Ruiz et al., 2021). In another study shoreline dynamics in the Hangzhou Bay in China were mapped using multi-temporal EO data (Chu et al., 2020). This work quantified both the spatial and temporal shoreline changes and assessed the link between shoreline changes and anthropogenic activities in a coastal area. Additionally, we conducted case studies in New Zealand dealing with the development of OBIA method to map landslides on time series of aerial photography. This included the assessment of revegetation rates of landslide scars (Spiekermann and Hölbling, 2019), and quantifying the effectiveness of erosion mitigation works, i.e., tree plantings, in pastoral hill country (Hölbling et al., 2019; Spiekermann et al., 2019). Small secondary studies dealt with the comparison and assessment of existing landslide inventories created after the 2015 Gorkha earthquake in Nepal (Meena et al., 2019a, 2019b). Moreover, a preliminary study aimed to gain a better understanding of morphometric control on the occurrence of landslides through process geomorphology and information derived from DEMs (Naranjo Bedoya et al., 2021).

\section{Outreach}

\subsection{Project website, logo and flyer}

We implemented a dedicated RiCoLa website (https://landslides-and-rivers.sbg.ac.at/) that provides all the necessary information about the project, including a news blog and a list of the publications and presentation (Figure 26). The news blog was regularly updated during the project lifetime, highlighting important project outcomes and events. 


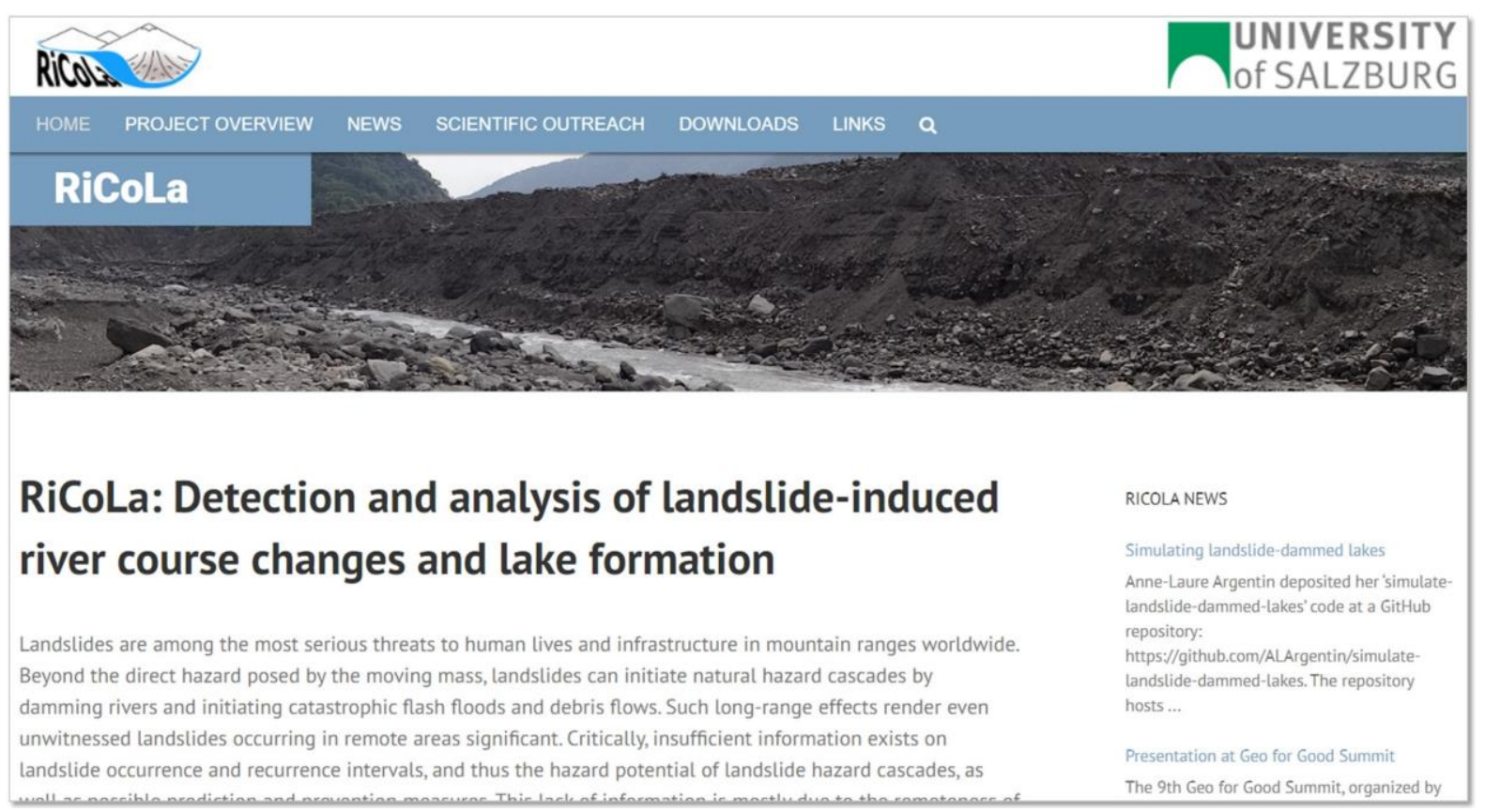

Figure 26: RiCoLa website (https://landslides-and-rivers.sbg.ac.at/).

\subsection{Peer-reviewed publications}

The outcomes of RiCoLa were published both in journals as well as conference proceedings. A range of publications, including six journal papers and 19 conference papers, have been produced to disseminate our final and intermediate results among the scientific community. Concepts and methods developed in RiCoLa could also be applied in thematically related studies, and thus, the value of the research in RiCoLa could be further demonstrated.

\subsubsection{Journal papers}

The following journal papers have been published or are currently in review:

1.) Abad, L., Hölbling, D., Spiekermann, R., Prasicek, G., Dabiri, Z., Argentin, A.-L., in review. Detecting landslide-dammed lakes on Sentinel-2 imagery and monitoring their spatiotemporal evolution after the Kaikōura earthquake in New Zealand. Natural Hazards.

2.) Argentin, A. L., Prasicek, G., Robl, J., Hergarten, S., Hölbling, D., Abad, L., \& Dabiri, Z., in review. The scaling of landslide-dammed lakes. Earth and Planetary Science Letters.

3.) Argentin, A. L., Robl, J., Prasicek, G., Hergarten, S., Hölbling, D., Abad, L., \& Dabiri, Z., 2020. Controls on the formation of potential landslide dams and dammed lakes in the Austrian Alps. Natural Hazards and Earth System Sciences Discussions, 1-29. https://doi.org/10.5194/nhess-2020-326

4.) Dabiri, Z., Hölbling, D., Abad, L., Helgason, J.K., Sæmundsson, P., Tiede, D., 2020. Assessment of Landslide-Induced Geomorphological Changes in Hítardalur Valley, Iceland, Using Sentinel-1 and Sentinel-2 Data. Applied Sciences, 10, 5848.

https://doi.org/10.3390/app10175848

5.) Hölbling, D., Abad, L., Dabiri, Z., Prasicek, G., Tsai, T.-T., Argentin, A.-L., 2020. Mapping and Analyzing the Evolution of the Butangbunasi Landslide Using Landsat Time Series 
with Respect to Heavy Rainfall Events during Typhoons. Applied Sciences, 10(2), 630. https://doi.org/10.3390/app10020630

6.) Gudiyangada Nachappa, T., Kienberger, S., Meena, S.R., Hölbling, D., Blaschke, T., 2020. Comparison and validation of per-pixel and object-based approaches for landslide susceptibility mapping. Geomatics, Natural Hazards and Risk, 11(1), 572-600. https://doi.org/10.1080/19475705.2020.1736190

7.) Chu, L., Oloo, F., Sudmanns, M., Tiede, D., Hölbling, D., Blaschke, T., Teleoaca, I., 2020. Monitoring long-term shoreline dynamics and human activities in the Hangzhou Bay, China, combining daytime and nighttime EO data. Big Earth Data, 4(3), 242-264. https://doi.org/10.1080/20964471.2020.1740491

\subsubsection{Conference contributions}

The following conference papers were published, including full and short papers, as well as abstracts:

1.) Argentin, A. L., Prasicek, G., Robl, J., Hergarten, S., Hölbling, D., Abad, L., \& Dabiri, Z., 2021. Size-frequency distribution of landslide-dammed lakes from a simulation approach (No. EGU21-9862). Copernicus Meetings.

2.) Hauthaler, T., Argentin, A. L., Robl, J., Prasicek, G., Hölbling, D., Hergarten, S., ... \& Dabiri, Z., 2021. Landslide dams acting as sediment traps: Example of the lake Hintersee, Berchtesgadener Land, south-eastern Germany (No. EGU21-12149). Copernicus Meetings.

3.) Naranjo Bedoya, K., Aristizábal, E., Hölbling, D., García, J., Aguilar, A., Ortiz, D., 2021. Approach for analyzing landslide and torrential flow hazard conditions in relation to landscape evolution in the northern Colombian Andes (No. EGU21-8508). Copernicus Meetings.

4.) Restrepo Ruiz, E., Lateltin, O., Linero Molina, C., Hölbling, D., 2021. Comparing two approaches for landslide susceptibility mapping - a case study in Freetown, Sierra Leone. XIII International Symposium on Landslides, 22-26 February, 8 p.

5.) Dabiri, Z., Hölbling, D., Abad, L., Helgason, J.K., Sæmundsson, P., Tiede, D., 2020. Generation of Multi-temporal DEMs from Sentinel-1 for Assessing Geomorphological Changes in the Hítardalur Valley, Western Iceland. GSA 2020 Connects Online. Geological Society of America Abstracts with Programs, 52, 6, 194-8.

6.) Abad, L., Hölbling, D., Spiekermann, R., Dabiri, Z., Prasicek, G., Argentin, A.-L., 2020. Mapping and monitoring of landslide-dammed lakes using Sentinel-2 time series - a case study after the 2016 Kaikōura Earthquake in New Zealand. EGU General Assembly 2020: Sharing Geoscience Online, EGU2020-572.

7.) Argentin, A.-L., Prasicek, G., Robl, J., Hölbling, D., Abad, L., Dabiri, Z., 2020. Landslide dam susceptibility in the Austrian Alps inferred from modelled landslides, potential valley damming and lake formation. EGU General Assembly 2020: Sharing Geoscience Online, EGU2020-8040.

8.) Dabiri, Z., Hölbling, D., Abad, L., Prasicek, G., Argentin, A.-L., Tsai, T.-T., 2019. An Objectbased Approach for Monitoring the Evolution of Landslide-Dammed Lakes and Detecting Triggering Landslides in Taiwan. The International Archives of the 
Photogrammetry, Remote Sensing and Spatial Information Sciences, XLII-3/W8, 103108.

9.) Dabiri, Z., Hölbling, D., Abad, L., Tiede, D., 2019. Assessment of Landslide-Induced Morphology Changes Using an Object-Based Image Analysis Approach: A Case Study of Hitardalur, Iceland. The International Archives of the Photogrammetry, Remote Sensing and Spatial Information Sciences, XLII-3/W8, 109-114.

10.) Hölbling, D., Dabiri, Z., Tsai, T.-T., Prasicek, G., Tsui, C.Y., Schäffer, L., Argentin, A.-L., Abad, L., 2019. Mapping the Evolution of the Butangbunasi Landslide, Taiwan, using Landsat Time Series. 27th IUGG General Assembly, Montreal, Canada, 8-18 July.

11.) Spiekermann, R., Hölbling, D., 2019. Semi-automated Farm-scale Assessment of Revegetation of Landslide Scars. 27th IUGG General Assembly, Montreal, Canada, 8-18 July.

12.) Chu, L., Oloo, F., Hölbling, D., Blaschke, T., 2019. Monitoring Long-term Influence of Human Activities on Shoreline Dynamics in the Hangzhou Bay, China, Using Google Earth Engine. ESA Living Planet Symposium 2019, Milan, Italy, 13-17 May.

13.) Meena, S.R., Ghorbanzadeh, O., Hölbling, D., 2019. Comparison of event-based landslide inventories: a case study from Gorkha earthquake 2015, Nepal. ESA Living Planet Symposium 2019, Milan, Italy, 13-17 May.

14.) Argentin, A.-L., Prasicek, G., Robl, J., Hölbling, D., 2019. Automated detection of past river-blocking landslides based on valley geometry. Geophysical Research Abstracts, Vol. 21, EGU General Assembly 2019-8617, Vienna, Austria.

15.) Hölbling, D., Spiekermann, R., Betts, H., 2019. Monitoring landslide erosion in dependence on land cover using advanced remote sensing techniques at multiple scales. Geophysical Research Abstracts, Vol. 21, EGU General Assembly 2019-3398-1, Vienna, Austria.

16.) Meena, S.R., Tavakkoli Piralilou, S., Hölbling, D., Blaschke, T., 2019. Qualitative and quantitative evaluation of earthquake-triggered landslide inventories in Nepal. Geophysical Research Abstracts, Vol. 21, EGU General Assembly 2019-4465, Vienna, Austria.

17.) Spiekermann, R., Hölbling, D., Betts, H., 2019. Hindcasting the impact of bio-physical erosion mitigation. Geophysical Research Abstracts, Vol. 21, EGU General Assembly 2019-3426-1, Vienna, Austria.

18.) Argentin, A.-L., Prasicek, G., Robl, J., Hölbling, D., Friedl, B., 2019. Influence of landslide dam history on the landform persistence. 18th ANZGG Conference, Inverloch, Australia, 4-8 February.

19.) Hölbling, D., Prasicek, G., Argentin, A.-L., Friedl, B., 2018. Detection of Landslide-induced River Course Changes and Lake Formation on Remote Sensing Data. AGU Fall Meeting 2018, Washington, D.C., USA, 10-14 December 2018.

20.) Argentin, A.-L., Prasicek, G., Robl, J., Hölbling, D., Friedl, B., 2018. A spatial causality method to identify the landslide-induced natural hazard cascades. IAMG 2018 - 19th Annual Conference, Olomouc, Czech Republic, 2-8 September 2018.

21.) Argentin, A.-L., Prasicek, G., Robl, J., Hölbling, D., Friedl, B., 2018. Detecting landslideinduced paleolakes and their impact on river course. Geophysical Research Abstracts, Vol. 20, EGU General Assembly 2018-6349-3, Vienna, Austria. 
22.) Friedl, B., Hölbling, D., Prasicek, G., Argentin, A.-L., Tsai, T.-T., 2018. Detection of landslide-dammed lakes and triggering landslides in Taiwan using Landsat imagery. Geophysical Research Abstracts, Vol. 20, EGU General Assembly 2018-14915, Vienna, Austria.

23.) Prasicek, G., Hölbling, D., Argentin, A.-L., Friedl, B., 2018. Detection and analysis of River course changes and lake formation - The RiCoLa Project. Geophysical Research Abstracts, Vol. 20, EGU General Assembly 2018-7768, Vienna, Austria.

\subsection{Presentations}

The project team members presented their research at several reputable, international conferences. Moreover, we gave invited talks that included a presentation of RiCoLA and the corresponding outcomes, for example, at Manaaki Whenua - Landcare Research in New Zealand, at the Czech Academy of Sciences in Czech Republic, and the University of Bergen in Norway, and presented outcomes at guest lectures at the University of Salzburg.

\subsubsection{Oral presentations}

1.) Hauthaler, T., Argentin, A.-L., Robl, J., Prasicek, G., Hölbling, D., Hergarten, S., Abad, L., Dabiri, Z., 2021. Landslide dams acting as sediment traps: Example of the lake Hintersee, Berchtesgadener Land, south-eastern Germany. EGU General Assembly 2021, April, 29.

2.) Argentin, A.-L., Prasicek, G., Robl, J., Hergarten, S., Hölbling, D., Abad, L., Dabiri, Z, 2021. Size-frequency distribution of landslide-dammed lakes from a simulation approach. EGU General Assembly 2021, April 27.

3.) Abad, L., Hölbling, D., 2020. Mapping and monitoring landslide-dammed lakes in Kaikōura, New Zealand, using the Google Earth Engine. Geo for Good Summit 2020, October 22.

4.) Abad, L., 2020. The role of geospatial technologies for mapping and monitoring natural hazards. Voices of Environmental Engineering, September 19.

5.) Hölbling, D., 2020. Landslide investigation with remote sensing. Presentation at "Lectures in GIScience: research progress and frontiers", University of Salzburg, Salzburg, Austria, May 18.

6.) Hölbling, D., 2020. Remote Sensing and OBIA for Landslide Mapping. Invited talk at Manaaki Whenua - Landcare Research, Palmerston North, New Zealand, February 11.

7.) Hölbling, D., 2019. Remote Sensing for Landslide Mapping: Examples, Opportunities and Challenges. Invited talk at the Department of Remote Sensing, CzechGlobe, Czech Academy of Sciences, Brno, Czech Republic, October 15.

8.) Dabiri, Z., Hölbling, D., Abad, L., Prasicek, G., Argentin, A.-L., Tsai, T.-T., 2019. An Objectbased Approach for Monitoring the Evolution of Landslide-Dammed Lakes and Detecting Triggering Landslides in Taiwan. Gi4DM, Prague, Czech Republic, 3-6 September.

9.) Dabiri, Z., Hölbling, D., Abad, L., Tiede, D., 2019. Assessment of Landslide-Induced Morphology Changes Using an Object-Based Image Analysis Approach: A Case Study of Hitardalur, Iceland. Gi4DM, Prague, Czech Republic, 3-6 September. 
10.) Hölbling, D., 2019. Landslide research @ Z_GIS: Landslide mapping and monitoring using remote sensing. Presentation at "Lectures in GIScience: research progress and frontiers", University of Salzburg, Salzburg, Austria, March 18.

11.) Argentin, A.-L., Prasicek, G., Robl, J., Hölbling, D., 2019. Influence of landslide dam history on the landform persistence. 18th ANZGG Conference, Inverloch, Australia, February 5.

12.) Hölbling, D., 2018. Landslide mapping using remote sensing: examples, opportunities and challenges. Invited talk at the Department of Geography, University of Bergen, Norway, September 27.

13.) Hölbling, D., 2018. Landslide Mapping. EO4Alps Summer School, Salzburg, Austria, 24 June -6 July.

14.) Hölbling, D., 2018. Landslide research @ Z_GIS: Remote sensing based landslide mapping and assessment. Presentation at "Lectures in GIScience: research progress and frontiers", University of Salzburg, Salzburg, Austria, April 23.

\subsubsection{Poster presentations}

1.) Abad, L., Hölbling, D., Spiekermann, R., Dabiri, Z., Prasicek, G., Argentin, A.-L., 2020. Mapping and monitoring of landslide-dammed lakes using Sentinel-2 time series - a case study after the 2016 Kaikōura Earthquake in New Zealand. EGU General Assembly 2020: Sharing Geoscience Online, 4-8 May.

2.) Argentin, A.-L., Prasicek, G., Robl, J., Hölbling, D., Abad, L., Dabiri, Z., 2020. Landslide dam susceptibility in the Austrian Alps inferred from modelled landslides, potential valley damming and lake formation. EGU General Assembly 2020: Sharing Geoscience Online, 4-8 May.

3.) Hölbling, D., Dabiri, Z., Tsai, T.-T., Prasicek, G., Tsui, C.Y., Schäffer, L., Argentin, A.-L., Abad, L., 2019. Mapping the Evolution of the Butangbunasi Landslide, Taiwan, using Landsat Time Series. 27th IUGG General Assembly, Montreal, Canada, 8-18 July.

4.) Spiekermann, R., Hölbling, D., 2019. Semi-automated Farm-scale Assessment of Revegetation of Landslide Scars. 27th IUGG General Assembly, Montreal, Canada, 8-18 July.

5.) Argentin, A.-L., Prasicek, G., Robl, J., Hölbling, D., 2019. Automated detection of past river-blocking landslides based on valley geometry. EGU General Assembly, Vienna, Austria, 7-12 April.

6.) Hölbling, D., Spiekermann, R., Betts, H., 2019. Monitoring landslide erosion in dependence on land cover using advanced remote sensing techniques at multiple scales. EGU General Assembly, Vienna, Austria, 7-12 April.

7.) Spiekermann, R., Hölbling, D., Betts, H., 2019. Hindcasting the impact of bio-physical erosion mitigation. EGU General Assembly, Vienna, Austria, 7-12 April.

8.) Hölbling, D., Prasicek, G., Argentin, A.-L., Friedl, B., 2018. Detection of Landslide-induced River Course Changes and Lake Formation on Remote Sensing Data. AGU Fall Meeting 2018, Washington, D.C., USA, 10-14 December.

9.) Argentin, A.-L., Prasicek, G., Robl, J., Hölbling, D., Friedl, B., 2018. A spatial causality method to identify the landslide-induced natural hazard cascades. IAMG 2018-19th Annual Conference, Olomouc, Czech Republic, 2-8 September. 
10.) Argentin, A.-L., Prasicek, G., Robl, J., Hölbling, D., Friedl, B., 2018. Detecting landslideinduced paleolakes and their impact on river course. EGU General Assembly, Vienna, Austria, 8-13 April.

11.) Friedl, B., Hölbling, D., Prasicek, G., Argentin, A.-L., Tsai, T.-T., 2018. Detection of landslide-dammed lakes and triggering landslides in Taiwan using Landsat imagery. EGU General Assembly, Vienna, Austria, 8-13 April.

12.) Prasicek, G., Hölbling, D., Argentin, A.-L., Friedl, B., 2018. Detection and analysis of River course changes and lake formation - The RiCoLa Project. EGU General Assembly, Vienna, Austria, 8-13 April.

\subsection{Workshops}

\subsubsection{Visit at the Disaster Prevention Education Center in Taiwan}

An important project milestone and dissemination activity was a 10-day research visit at the Disaster Prevention Education Center in Tainan, Taiwan, in mid-November 2018. During the visit several dissemination actitivites took place, feedback from local experts was gathered during workshops and field trips, and ideas for further collaboration were collected. For details see section 2.3.1.

\subsection{Further dissemination activities}

\subsubsection{Online dissemination}

Next to the project website, online visibility was achieved by project summaries presented at the institutional websites (http://geomorphology.sbg.ac.at/research/projects/ricola/ and https://zgis.at/ricola-2017-2020/), and through a respective page on ResearchGate (https://www.researchgate.net/project/RiCoLa-Detection-and-analysis-of-landslide-

induced-river-course-changes-and-lake-formation). RiCoLa was also presented in the Z_GIS Newsletter of January 2018. Moreover, the research conducted on the Butangbunasi landslide in Taiwan (Hölbling et al., 2020) has been highlighted in the Trimble eCognition blog (https://ecognition.blog/mapping-the-evolution-of-a-landslide/).

The results presented at the EGU 2020: Sharing Geoscience Online have been highlighted on the websites of the ORF (Austrian Broadcasting Corporation) - "Risikolandkarte für Flussblockaden" (https://science.orf.at/stories/3200699/), Der Standard (Austrian daily newspaper) - "Wo Erdrutsche zu gefährlichen Flussblockaden führen können" (https://www.derstandard.at/story/2000117289457/wo-erdrutsche-zu-gefaehrlichenflussblockaden-fuehren-koennen) and the Austria Press Agency (APA) - "Forscher zeichneten Risiko-Landkarte für Erdrutsch-Flussblockaden" (https://science.apa.at/rubrik/natur und technik/Forscher zeichneten RisikoLandkarte fuer Erdrutsch-Flussblockaden/SCI 20200505 SCl39391351454441262) . 


\subsubsection{Project flyer and logo}

We created a project brochure, which is available both in digital format at the project website and as a printed edition (Figure 27). The printed brochure was disseminated at conferences and workshops. Moreover, a project logo was designed that was used on the website and in presentations to ensure a corporate identity.
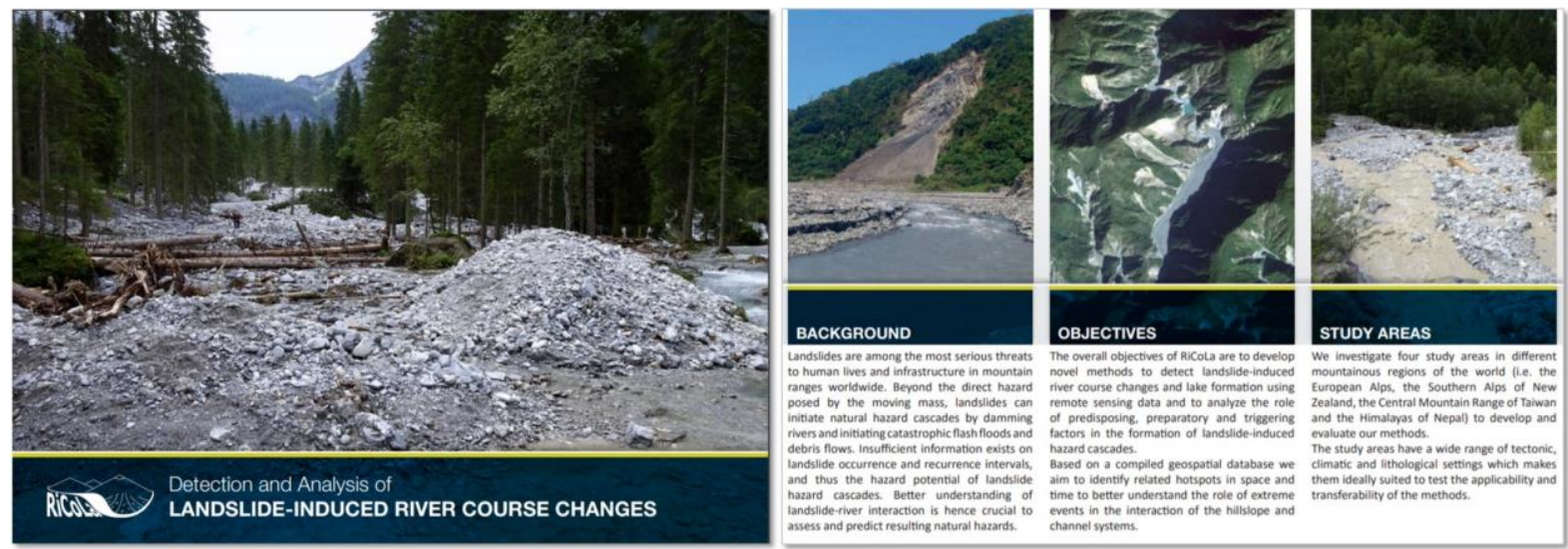

Figure 27: RiCoLa brochure.

\subsubsection{Popular science story}

"Shifting approaches to landslides" - a cover story by M. J. Wagner about D. Hölbling's work on landslide research using remote sensing data was published in the LIDAR Magazine (Oct/Nov 2017 Issue; https://lidarmag.com/2017/10/25/shifting-approaches-to-landslides/) and the American Surveyor Magazine (Nov 2017 Issue; https://amerisurv.com/2017/10/21/shifting-approaches-to-landslides/). The article highlights also the research conducted in the frame of RiCoLa.

\section{References}

Adams, J., 1981. Earthquake-dammed lakes in New Zealand. Geology, 9(5), 215.

Behling, R., Roessner, S., Segl, K., Kleinschmit, B., Kaufmann, H., 2014. Robust automated image coregistration of optical multi-sensor time series data: Database generation for multi-temporal landslide detection. Remote Sensing, 6, 2572-2600.

Chu, L., Oloo, F., Sudmanns, M., Tiede, D., Hölbling, D., Blaschke, T., Teleoaca, I., 2020. Monitoring long-term shoreline dynamics and human activities in the Hangzhou Bay, China, combining daytime and nighttime EO data. Big Earth Data, 4(3), 242-264.

Cui, P., Zhu, Y., Han, Y., Chen, X., \& Zhuang, J., 2009. The 12 May Wenchuan earthquake-induced landslide lakes: distribution and preliminary risk evaluation. Landslides, 6(3), 209-223.

Dabiri, Z., Hölbling, D., Abad, L., Helgason, J.K., Sæmundsson, P., Tiede, D., 2020. Assessment of Landslide-Induced Geomorphological Changes in Hítardalur Valley, Iceland, Using Sentinel-1 and Sentinel-2 Data. Applied Sciences, 10, 5848. 
Dellow, S., Massey, C. I., Cox, S.C., Archibald, G., Begg, J., Bruce, Z., Carey, J., Davidson, J., Pasqua, F.D., Glassey, P.J., Hill, M., Jones, K., Lyndsell, B., Lukovic, B., McColl, S., Rattenbury, M.S., Read, S., Rosser, B., Singeisen, C., Townsend, D., Villamor, P., Villeneuve, M., Godt, J.W., Jibson, R.W., Allstadt, K.E., Rengers, F.K., Wartman, J., Rathje, E.M., Sitar, N., Adda, A.Z., Manousakis, J., Little, M., 2017. Landslides caused by the Mw7.8 Kaikōura earthquake and the immediate response. Bulletin of the New Zealand Society for Earthquake Engineering.

Helgason, J.K., Sæmundsson, P., Drouin, V., Jóhannesson, T., 2019. The Hítardalur landslide in West Iceland in July 2018. Geophysical Research Abstracts, Vol. 21, EGU General Assembly, Vienna, Austria, 7-12 April 2019.

Donchyts, G., Schellekens, J., Winsemius, H., Eisemann, E., \& van de Giesen, N., 2016. A 30 m resolution surface water mask including estimation of positional and thematic differences using Landsat 8, SRTM and OpenStreetMap: A case study in the Murray-Darling basin, Australia. Remote Sensing, 8(5).

Eisank, C., Hölbling, D., Friedl, B., Chen, Y.-C., Chang, K.-T., 2014. Expert knowledge for object-based landslide mapping in Taiwan. South-Eastern European Journal of Earth Observation and Geomatics, 3, 347-350.

Finnegan, N. J., Broudy, K. N., Nereson, A. L., Roering, J. J., Handwerger, A. L., \& Bennett, G., 2019. River channel width controls blocking by slow-moving landslides in California's Franciscan mélange. Earth Surface Dynamics, 7(3), 879-894.

Flint, J. J., 1974. Stream gradient as a function of order, magnitude, and discharge. Water Resources Research, 10(5), 969-973.

Freitas, P., Vieira, G., Canário, J., Folhas, D., \& Vincent, W., 2019. Identification of a Threshold Minimum Area for Reflectance Retrieval from Thermokarst Lakes and Ponds Using Full-Pixel Data from Sentinel-2. Remote Sensing, 11(6), 657.

Friedl, B., Hölbling, D., Prasicek, G., Argentin, A.-L., Tsai, T.-T., 2018. Detection of landslide-dammed lakes and triggering landslides in Taiwan using Landsat imagery. Geophysical Research Abstracts, Vol. 20, EGU General Assembly 2018-14915, Vienna, Austria.

Gorelick, N., Hancher, M., Dixon, M., Ilyushchenko, S., Thau, D., \& Moore, R., 2017. Google Earth Engine: Planetary-scale geospatial analysis for everyone. Remote Sensing of Environment, 202, 18-27.

Gudiyangada Nachappa, T., Kienberger, S., Meena, S.R., Hölbling, D., Blaschke, T., 2020. Comparison and validation of per-pixel and object-based approaches for landslide susceptibility mapping. Geomatics, Natural Hazards and Risk, 11(1), 572-600.

Hergarten, S., 2012. Topography-based modeling of large rockfalls and application to hazard assessment. Geophysical research letters, 39(13).

Herman, F., Seward, D., Valla, P. G., Carter, A., Kohn, B., Willett, S. D., \& Ehlers, T. A., 2013. Worldwide acceleration of mountain erosion under a cooling climate. Nature, 504(7480), 423-426.

Hölbling, D., Abad, L., Dabiri, Z., Prasicek, G., Tsai, T.-T., Argentin, A.-L., 2020. Mapping and Analyzing the Evolution of the Butangbunasi Landslide Using Landsat Time Series with Respect to Heavy Rainfall Events during Typhoons. Applied Sciences, 10(2), 630. 
Hölbling, D., Betts, H., Spiekermann, R., Phillips, C., 2016. Identifying Spatio-Temporal Landslide Hotspots on North Island, New Zealand, by Analyzing Historical and Recent Aerial Photography. Geosciences, 6, 48.

Hölbling, D., Dabiri, Z., Tsai, T.-T., Prasicek, G., Tsui, C.Y., Schäffer, L., Argentin, A.-L., Abad, L., 2019. Mapping the Evolution of the Butangbunasi Landslide, Taiwan, using Landsat Time Series. 27th IUGG General Assembly, Montreal, Canada, 8-18 July.

Hölbling, D., Friedl, B., Eisank, C., 2015. An object-based approach for semi-automated landslide change detection and attribution of changes to landslide classes in northern Taiwan. Earth Science Informatics, 8, 327-335.

Hölbling, D., Füreder, P., Antolini, F., Cigna, F., Casagli, N., Lang, S., 2012. A Semi-Automated ObjectBased Approach for Landslide Detection Validated by Persistent Scatterer Interferometry Measures and Landslide Inventories. Remote Sensing, 4, 1310-1336.

Hölbling, D., Spiekermann, R., Betts, H., 2019. Monitoring landslide erosion in dependence on land cover using advanced remote sensing techniques at multiple scales. Geophysical Research Abstracts, Vol. 21, EGU General Assembly 2019-3398-1, Vienna, Austria.

Keyport, R.N., Oommen, T., Martha, T.R., Sajinkumar, K.S., Gierke, J.S., 2018. A comparative analysis of pixel- and object-based detection of landslides from very high-resolution images. International Journal of Applied Earth Observation and Geoinformation, 64, 1-11.

Klappacher, W., \& Knapczyk, H. (Eds.), 1979. Salzburger Höhlenbuch. Landesverein für Höhlenkunde in Salzburg.

Korup, O., 2005. Geomorphic imprint of landslides on alpine river systems, southwest New Zealand. Earth Surface Processes and Landforms, 30(7), 783-800.

Kuhn, C.: Austrian Rockslides http://geol-info.at/index.htm, visited 2020.07.27.

Lahousse, T., Chang, K.T., Lin, Y.H., 2011. Landslide mapping with multi-scale object-based image analysis-a case study in the Baichi watershed, Taiwan. Natural Hazards and Earth System Sciences, 11, $2715-2726$.

Lee, J.-S. Refined filtering of image noise using local statistics. Computer Graphics and Image Processing. 1981, 15, 380-389.

Lu, P., Stumpf, A., Kerle, N., Casagli, N., 2011. Object-oriented change detection for landslide rapid mapping. IEEE Geoscience and Remote Sensing Letters, 8, 701-705.

Martha, T.R., Kerle, N., Jetten, V., van Westen, C.J., Kumar, K.V., 2010. Characterising spectral, spatial and morphometric properties of landslides for semi-automatic detection using object-oriented methods. Geomorphology, 116, 24-36.

Massey, C. I., Townsend, D., Dellow, S., Lukovic, B., Rosser, B., Archibald, G., Villeneuve, M., Davidson, J., Jones, K., Morgenstern, R., Strong, D. T., Lyndsell, B., Tunnicliffe, J., Carey, J., \& McColl, S., 2018. Kaikoura Earthquake Short-Term Project: Landslide inventory and landslide dam assessments. In GNS Science Report 2018/19. 
Meena, S.R., Ghorbanzadeh, O., Hölbling, D., 2019a. Comparison of event-based landslide inventories: a case study from Gorkha earthquake 2015, Nepal. ESA Living Planet Symposium 2019, Milan, Italy, 13-17 May.

Meena, S.R., Tavakkoli Piralilou, S., Hölbling, D., Blaschke, T., 2019b. Qualitative and quantitative evaluation of earthquake-triggered landslide inventories in Nepal. Geophysical Research Abstracts, Vol. 21, EGU General Assembly 2019-4465, Vienna, Austria.

Moosavi, V., Talebi, A., Shirmohammadi, B., 2014. Producing a landslide inventory map using pixelbased and object-oriented approaches optimized by Taguchi method. Geomorphology, 204, 646-656.

Nichol, J., \& Wong, M. S., 2005. Satellite remote sensing for detailed landslide inventories using change detection and image fusion. International journal of remote sensing, 26(9), 1913-1926.

Pekel, J.-F., Cottam, A., Gorelick, N., \& Belward, A. S., 2016. High-resolution mapping of global surface water and its long-term changes. Nature, 540(7633), 418-422.

Plank, S., Hölbling, D., Eisank, C., Friedl, B., Martinis, S., Twele, A., 2015. Comparing object-based landslide detection methods based on polarimetric SAR and optical satellite imagery-A case study in Taiwan. Proceedings of the 7th International Workshop on Science and Applications of SAR Polarimetry and Polarimetric Interferometry, POLinSAR, Frascati, Italy, 26-30 January 2015, pp. 1-5.

Popinet, S., 2003. Gerris: a tree-based adaptive solver for the incompressible Euler equations in complex geometries. Journal of Computational Physics, 190(2), 572-600.

Rau, J.-Y., Jhan, J.-P., Rau, R.-J., 2014. Semiautomatic object-oriented landslide recognition scheme from multisensor optical imagery and DEM. IEEE Transactions on Geoscience and Remote Sensing, 52, 1336-1349.

Reichenbach, P., Rossi, M., Malamud, B. D., Mihir, M., \& Guzzetti, F., 2018. A review of statisticallybased landslide susceptibility models. Earth-Science Reviews, 180, 60-91.

Schrott, L., Hufschmidt, G., Hankammer, M., Hoffmann, T., \& Dikau, R., 2003. Spatial distribution of sediment storage types and quantification of valley fill deposits in an alpine basin, Reintal, Bavarian Alps, Germany. Geomorphology, 55(1-4), 45-63.

Spiekermann, R., Hölbling, D., 2019. Semi-automated Farm-scale Assessment of Revegetation of Landslide Scars. 27th IUGG General Assembly, Montreal, Canada, 8-18 July.

Spiekermann, R., Hölbling, D., Betts, H., 2019. Hindcasting the impact of bio-physical erosion mitigation. Geophysical Research Abstracts, Vol. 21, EGU General Assembly 2019-3426-1, Vienna, Austria.

Stähli, M., Sättele, M., Huggel, C., McArdell, B. W., Lehmann, P., Van Herwijnen, A., ... \& Springman, S. M., 2015. Monitoring and prediction in early warning systems for rapid mass movements. Natural Hazards and Earth System Sciences, 15(4), 905-917.

Wood, J., 2009. Geomorphometry in landserf. Developments in soil science, 33, 333-349. 
$\mathrm{Xu}, \mathrm{H} ., 2$ 2006. Modification of normalised difference water index (NDWI) to enhance open water features in remotely sensed imagery. International Journal of Remote Sensing, 27(14), 3025-3033. 